\title{
Seismic Microzonation Study of South Asian Cities and Its Implications to Urban Risk Resiliency under Climate Change Scenario
}

\author{
O. P. Mishra1,2 \\ ${ }^{1}$ National Center for Seismology, Ministry of Earth Sciences, New Delhi, India \\ ${ }^{2}$ Formerly SAARC Disaster Management Centre, New Delhi (Now Relocated at Gandhinagar), India \\ Email: omp.mishra@nic.in,opmishra2010.saarc@gmail.com
}

How to cite this paper: Mishra, O.P. (2020) Seismic Microzonation Study of South Asian Cities and Its Implications to Urban Risk Resiliency under Climate Change Scenario. International Journal of Geosciences, 11, 197-237.

https://doi.org/10.4236/ijg.2020.114012

Received: December 23, 2019

Accepted: April 24, 2020

Published: April 27, 2020

Copyright $(2) 2020$ by author(s) and Scientific Research Publishing Inc. This work is licensed under the Creative Commons Attribution International License (CC BY 4.0).

http://creativecommons.org/licenses/by/4.0/

\begin{abstract}
In this study, an attempt has been made to review the existing framework of earthquake risk resiliency for the urban agglomerates of South Asian earthquake-prone countries (Afghanistan; Bangladesh; Bhutan, India, and Pakistan) with aim of suggesting a plausible model for earthquake risk resiliency for urban agglomerates of the region under the influence of uncontrollable climate change scenario. We demonstrated that the existing infrastructures can be retrofitted to mitigate and reduce the nature and extent of damages to structures to the greater extent whilst site response based comprehensive seismic microzonation is very much required for new settlements and for long-term sustainable urban planning by adopting multi-disciplinary investigations using integrated tools consisted of geophysical, geological, and geotechnical methodologies, which in turn help understand how and why underneath sub-surface layers get amplified to cause destruction of buildings and severe damages to critical infrastructures of South Asian Cities. It is inferred that implementation of fourth level comprehensive seismic Micro, Nano, Pico and Femto zonation study for almost all strategic cities of South Asia is a need of an hour in particular, and of the seismically prone regions of the world, in general, which would be helpful for generating a series of new parameters for development of multi-dimensional risk resilient building design codes for the safer and sustainable infrastructures of urban settlement. The methodology has wide-scale applicability to different kinds of structures and typology of the buildings.
\end{abstract}

\section{Keywords}

South Asia, Seismic Microzonation, Site Response, Climate Change, Urban Agglomerate, Urban Risk Resiliency 


\section{Introduction}

It is correctly said that "Earthquakes don't kill people; it is the structure that kills people during the shaking of an earthquake". Till today, the prediction of Earthquakes is neither possible nor be authenticated based on their so far known parameters as because the present state of knowledge is inadequate to understand the physics of earthquake genesis. Hence, we are not able to predict earthquake due to its lack of diagnostic precursors. That is why in absence of earthquake prediction there is always a serious threat to losses of lives and property, besides a serious scope of environmental degradation in the earthquake prone regions where earthquake strucks in the world. As mentioned above, the involvement of the complex physics in generating processes of earthquakes made our present endeavour of developing pre-earthquake early warning is not only the toughest task but the task is very much challenging to us, despite a significant breakthrough in development of post-earthquake early warning that used to be issued after the rupture gets initiated when the earthquake already rocked at the place.

South Asia is the hotspot of almost all natural disasters where huge recurrence losses of both people and property reported to occur regularly during the moderate to strong earthquake shakings in the region [1]. Owing to the complex seismotectonic settings and appreciable seismic impedance contrasts between the varying soil strata and the bedrock, buried basins or complex geometries of the sub-surface formations in association with the topographic effects coupled with the seismic attenuative behaviour of the geological structures with majority of un-engineered structures, South Asia is listed among the countries of extremely vulnerable to seismic hazards in the world. It is, therefore realized that losses of flora, faunas, and infrastructures due to earthquakes can be reduced either by development of pre-earthquake early warning system with adequate response time, or, by development of earthquake risk resilient structures that can withstand the amount of earthquake shakings and get those structures safer from collapse or to avoid any degree of damages to structures during the earthquake. Nonetheless, the post-earthquake early warning with sufficient actionable response time $(50-70 \mathrm{sec})$ is not adequate to mitigate earthquake risks to structures to a greater extent even today as the post-earthquake warning so far received by stakeholders for the local to regional earthquakes are not of higher reliability. It is so because the post-earthquake early warning is happening only after the occurrence or onset of the rupture initiation that triggers the event and we extract information only about the onset of secondary seismic body wave and subsequent surface and converted seismic phases. Secondly, the present seismic Hazard Macrozonation maps of South Asian countries under which different cities correspond to a particular zone of seismic hazards is based on intensity law, which is just a qualitative in nature, representing no actual damage pattern of infrastructures for the given typology, design and materials used in the constructions for the particular city during the earthquake shaking of given magni- 
tude. It is observed that the damage scenario of entire buildings for similar constructions with similar building materials, and for similar design for entire structures of a particular city that falls in a particular Seismic Hazard Zone found never to be the same for a given earthquake of specific magnitude and strength. Such observation sheds an important light on the fact that there are other parameters which control the degree of damage to structures that have not been considered or taken into account for the development of the existing Seismic Hazard Zonation maps for countries of South Asia region. Keeping all these genuine constraints as per the disaster risk management guidelines into account, it has become pertinent to undertake extensive study on seismic microzonation of the city of a country under south Asia region by dividing a macro-zone into several smaller zones with dense grids as the observational points for making assessments of several geophysical, seismological, geotechnical parameters that can be used for development of a comprehensive earthquake risk resilient structural design codes for different cities located in the vicinity of earthquake source zones or in the seismic hazard zones, which can be useful for long-term policy planning under the sound and safer strategic mission of a country for constructing sustainable and earthquake risk resilient structures.

In the present study, an attempt has been made to understand earthquake/ seismogenic potential of south Asia and impacts of earthquakes on structures/ infrastructures of south Asian cities for suggesting earthquake risk mitigation strategy by studying urban agglomerates of South Asian counties. Nonetheless, the job of achieving risk resiliency of cities of South Asia has become very challenging and a herculean task for geoscientists and civil engineers.

\section{Earthquake Potential of South Asia and Earthquake Impacts}

South Asia region (SAR) has eight countries, namely, Afghanistan, Bangladesh, Bhutan, India, Nepal, Maldives, Pakistan, and Sri Lanka as the main constituent of South Asia Association for Regional Cooperation (SAARC), an important inter-governmental regional organization of Asia-Pacific as well as of the world. SAR is regarded as one of the most earthquake prone regions in the world. Complex seismotectonic settings of South Asia are associated with factory of faults, ledger-folio of lineaments and warehouse of weak zones (Figure 1), which make the region most apt for huge seismic potential for several moderate-strong to great earthquakes since years.

It is observed that six out of the eight countries of South Asia, namely Afghanistan, Pakistan, India, Nepal, Bhutan and Bangladesh are located within most seismically active Himalayan-Hindukush belt which has witnessed some of the worst earthquakes recorded in the annals of Seismology of South Asia (Table 1; [2]) that witnessed series of micro to macro earthquakes of varying strengths. Parts of Indian peninsula and the island territory of Andaman \& Nicobar are also associated 


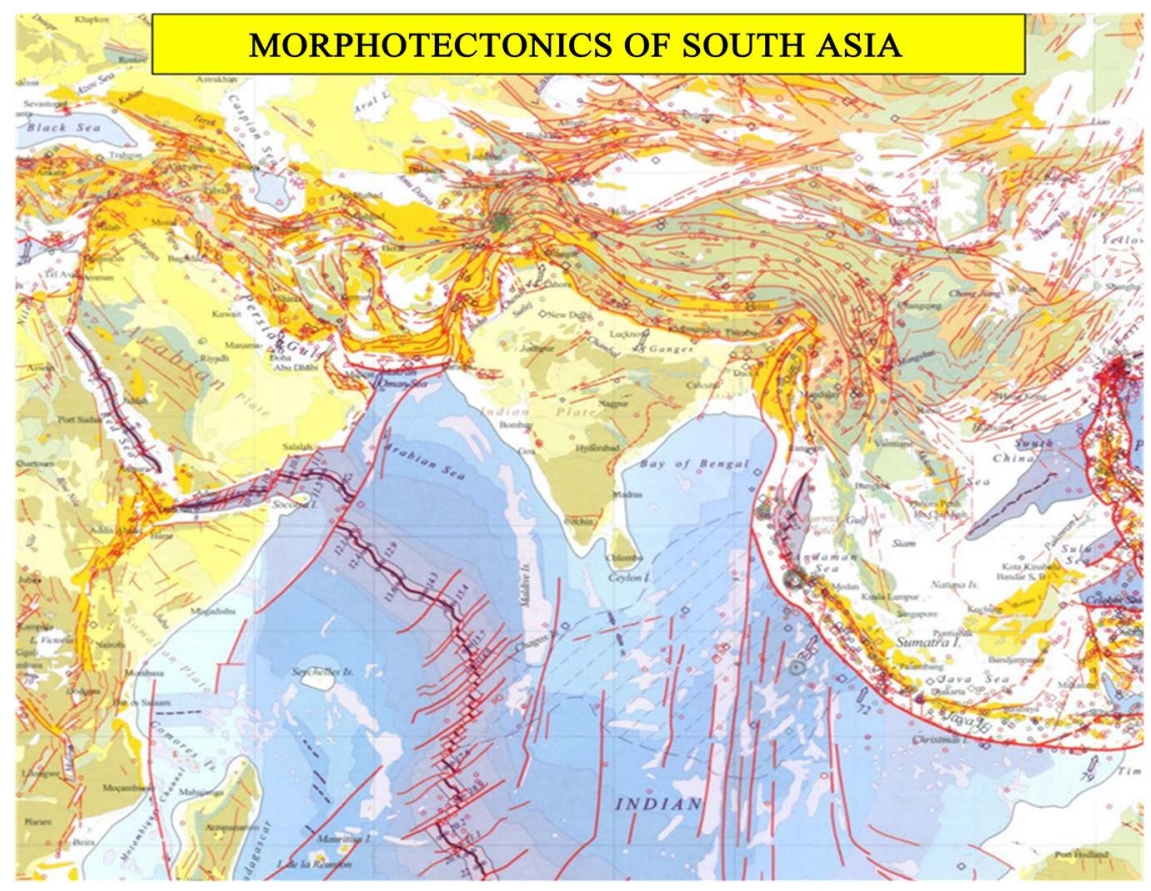

Figure 1. Geo-morphotectonic set up of South Asia associated with faults, lineaments, rifts, and ridges denoted by broken and thick lines along with past seismicity (in circles) [3].

Table 1. The Strongest Earthquakes (M > 7) of South Asia since 1900.

\begin{tabular}{cccccc}
\hline & Date & Mw & Latitude & Longitude & Location \\
\hline 1 & 26 December 2004 & 9.1 & 03.29 & 95.98 & Sumatra-Andaman arc \\
2 & 15 August 1950 & 8.6 & 28.38 & 96.76 & Chayu-Upper Assam \\
3 & 15 January 1934 & 8.1 & 27.55 & 87.09 & Nepal-Bihar border \\
4 & 27 November 1945 & 8.0 & 25.15 & 63.48 & Makran Coast, Pakistan \\
5 & 25 April 2015 & 7.9 & 28.14 & 84.70 & Gorkha District, Nepal \\
6 & 30 May 1935 & 7.8 & 28.87 & 66.40 & Quetta, Balochistan \\
7 & 4 April 1905 & 7.8 & 33.00 & 76.00 & Kangra, Himachal Pradesh \\
8 & 26 June 1941 & 7.7 & 12.40 & 92.50 & Middle Andaman Island \\
9 & 26 January 2001 & 7.7 & 23.44 & 70.31 & Bhuj, Gujarat \\
10 & 8 October 2005 & 7.6 & 34.43 & 73.53 & Kashmir-Kohistan \\
11 & 29 February 1944 & 7.4 & 00.30 & 75.30 & Near Maldive Islands \\
\hline
\end{tabular}

with known and hidden major seismogenic faults, which have history of rupturing in the past [2] [4] [5]. It is pertinent to note that the remaining two coastal countries of SAR, namely, Sri Lanka and Maldives are vulnerable to tsunamigenic earthquakes in the Indian Ocean, besides majority of the coastal areas of Bangladesh, India and Pakistan are similarly vulnerable to sub-oceanic earthquakes beneath the Indian Ocean [2].

Earthquakes have caused heavy damages in terms of deaths, injuries, destruction of habitat and disruption of economic activity that have left scars on a large 
section of population in wide areas (Table 2; [2]). It is proven fact that the potentially catastrophic consequences of largely unpredictable earthquakes, particularly on the growing urban areas of different seismic zones of South Asia allow countries of the region to use their resources, expertise and strengths to work for making those cities risk resilient, which are located in the vicinity of earthquake prone belts of SAR. Since, these cities are under a serious threat due to the growing population, rampant, raipd, unplanned, and haphazard urbanisation. The seismic networks installed in the countries of South Asia are found to be very much sparse and are not sufficient for determining earthquakes parameters for the region. Historical earthquake data of SAR recorded over centuries are also found to be inadequate to understand the nature of past damaging history vis-à-vis the sub-surface causative factors that led to damages to structures in the source zones. Based on the analysis and inference from available data the frequency and magnitude of earthquakes in South Asia, it is observed that varying number of earthquakes of varying magnitudes with certain interval of years (Table 3) have uneven and erratic distribution to impact the source zones differently.

In terms of fatalities, only earthquakes of M 6 and above are known to have caused damages to lives and property provided depths of source zones will not be shallower, although there are several pieces of evidence that suggest earthquakes of lesser magnitudes did cause cracks in structures and trigger landslides. The cumulative effects of such damaging earthquakes were found fatal, but very few empirical studies on such damages are available, which constrain us to infer plausible mechanism of earthquake generating processes to understand the nature of mainshock rupture propagation.

Table 2. Some of the significant fatal earthquakes $(M \geq 6.0)$ of South Asia during the past 100 years [2].

\begin{tabular}{cccc}
\hline Year & Location & Magnitude & Deaths in south Asia \\
\hline 2015 & Gorkha & 7.9 & $9500+$ \\
2005 & Kashmir & 7.6 & 75,900 \\
2004 & Sumatra & 9.1 & $55,000+$ \\
2001 & Bhuj & 7.7 & 13,845 \\
1999 & Chamoli & 6.4 & 103 \\
1998 & Afghanistan & 6.6 & 4000 \\
1998 & Afghanistan & 6.1 & 2323 \\
1993 & Latur-Killari & 6.4 & 10,000 \\
1991 & Uttarkashi & 6.3 & 768 \\
1974 & Northern Pakistan & 6.2 & 5300 \\
1956 & Anjar & 6.0 & 115 \\
1935 & Quetta & 7.3 & 35,000 \\
1934 & Nepal-Bihar & 8.1 & 10,653 \\
1905 & Kangra & 7.8 & 28,000 \\
\hline
\end{tabular}


Table 3. Frequency and magnitude of earthquakes in South Asia [2].

\begin{tabular}{ccc}
\hline Descriptor & Magnitude & Frequency \\
\hline Great & $8+$ & 1 in 25 years \\
Major & $7-7.9$ & 1 in 16 years \\
Strong & $6-6.9$ & 1 in 4 years \\
Moderate & $5-5.9$ & 35 every year \\
Light & $4-4.9$ & 1550 every year (estimated) \\
Minor/Micro & $3-3.9$ & 5500 every year (estimated) \\
Very Minor/Very Micro & $2-2.9$ & 100,000 every year (estimated) \\
\hline
\end{tabular}

It is clear that in the recent years, fatality in terms of loss of lives due to earthquakes is getting increased exponentially. It is expected that extent of fatality would be enormous in the years to come, which in turn exposes the diverse strata of vulnerable population of south Asia associated with poverty, illiteracy, and rampant and unscientific haphazard urbanization that may augment the earthquake risk scenario more complex in absence of feasible strategy for earthquake risk resiliency. So far major catastrophic earthquakes of South Asia have mostly occurred in low population density of semi-urban or rural areas. Impacts of such earthquakes nearer the urban centres shall be far more devastating for which the countries of the region are not at all prepared. It is therefore extremely important to assess the risks of earthquake in a comprehensive manner so that appropriate measures can be taken up to reduce these risks as the response for the pre-earthquake disaster risks.

\section{Urbanization and Earthquake Risk Vulnerability}

It is observed that the decline of many mega cities in the developed or even the developing world is the two aspects of socio-economic expedition of the region. A UNHABITAT made an extensive analysis in 1403 cities of the developing world shows that 143 cities or $10.2 \%$ of the total data collected on cities have experienced a reduction in population between the year 1990 and 2000. The 12th edition of Demographic World Urban Areas report of 2016 showed uneven demographic distribution of the urban areas of the world among different continents, namely, Asia, Africa, South America, Europe, North America, and Oceania. It is also observed that more than half of the population of large urban areas of 500,000 and over, is in Asia (56.6\%), living in 532 cities of the 1009 large urban areas of the world as shown in Figure 2 \& Figure 3.

The period between the year 2005 and 2010, has witnessed urban population growth over-taking the rural population in the world (from $49 \%-51 \%$ ). Asia-pacific region has witnessed the fastest urban growth at the rate of $2 \%$ per annum (2005-2010), which suggests that urbanization is a major factor that bringing a sea change in human settlements and exposing to the physical vulnerability to earthquake risks. Over half of the world's populations, constituting 


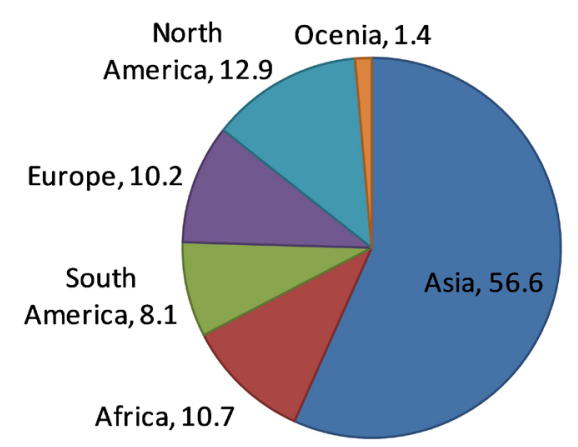

Figure 2. Distribution of Large Urban Area Population of the Continent: (500,000 and over) (Adapted from [6]).

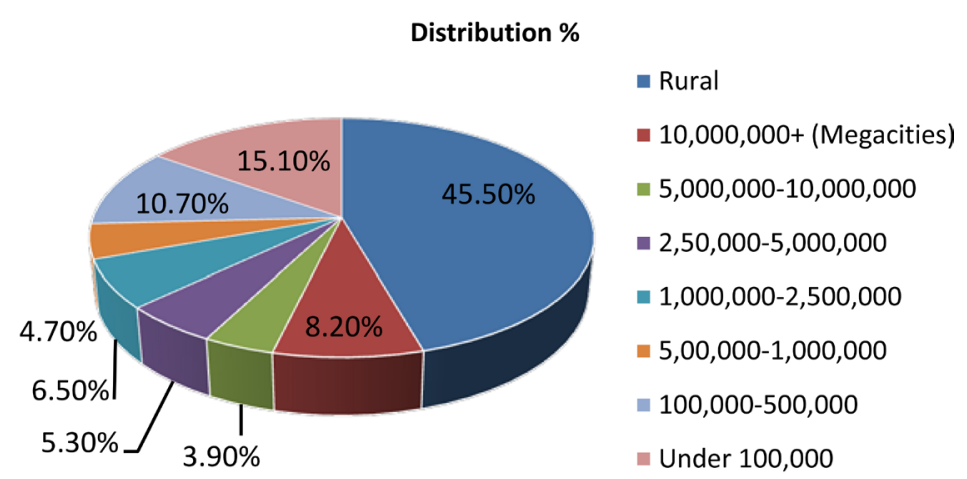

Figure 3. World Population Distribution (Urban \& Rural 2016) (Adapted from [6]).

about 3.3 billion people were living in the urban areas. It is estimated that about $60 \%$ of the world's population will be urbanized by 2030 . There are currently 19 megacities in the world and are expected to be 27 by 2020 . Over half of this growth will be in Asia where the world's economic geography is now shifting. Such fast trend of conversion of cities into megacities suggests that a set of appropriate engineering-based city settlement and management mechanisms is required for its sustainability under climate change scenario. The global survey of urban agglomeration conducted by UNESCAPE in the year 2009-2010 showed that Asia is a home of significantly largest urban agglomerates. The urban agglomerations of Bangladesh, India, and Pakistan of SAR now occupy their international rank within 10 among the world-ranking list. It is however a sad commentary on growth particularly in Asia where more than $25 \%$ of urban population accounts for slums [6], and contributed towards the urban risk vulnerability because of poorly built structured and non-structural set ups.

\section{Trends of Urbanization in SAR}

According to the United Nation's estimates, South Asia's urban population is expected to reach one billion by the year 2030 that may aggravate the earthquake risk vulnerability scenario of South Asia Region [6] [7]. That is about 120 percent increase in three decades beginning with the year 2000. Three countries namely India, Pakistan, Bangladesh would continue to accommodate an overwhelming 95.4 percent of the regions urban population by 2030 as compared to 
97.3 percent in the year 2000. This marginal decline in their share is because of relatively faster increase in the urban population of smaller countries like Afghanistan, Bhutan and Nepal. However, the growth rates of urban population are estimated to decline in the successive decades in all the countries of the region, except India and Sri Lanka. Figure $4 \&$ Figure 5 indicate Index and annual growth rate (\%) of urban population in South Asian countries for 1990-2012 [6].

It may be observed from Figure 6 that the level of urbanisation in SAR is increasing with alarming rate for Indian subcontinent, mainly of Bangladesh, India, Pakistan, the percentage urban population is expected to rise appreciably for Bangladesh, Pakistan, and India by the year 2030 in SAR [6]. These observations shed light on the fact that urban cities of SAR are going to be more vulnerable to earthquake risks due to growth of unscientific and haphazard urban cities.

\section{Earthquake Risk Assessment of South Asia}

It is important to note that the urban population of South Asia is anticipated to touch 750 million by 2020, thereby almost doubling the risk to urban population in high hazard areas across Afghanistan, Pakistan, India, Nepal, Bhutan and

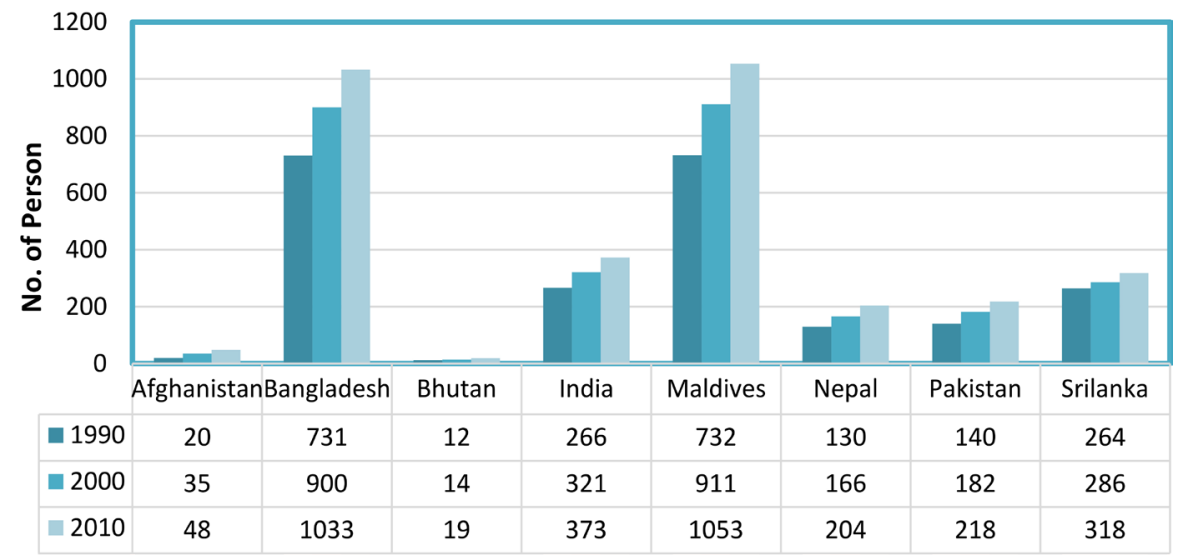

Figure 4. Index of urban Population of South Asia (population per sq.km, 1990-2010) (Adapted from [6]).

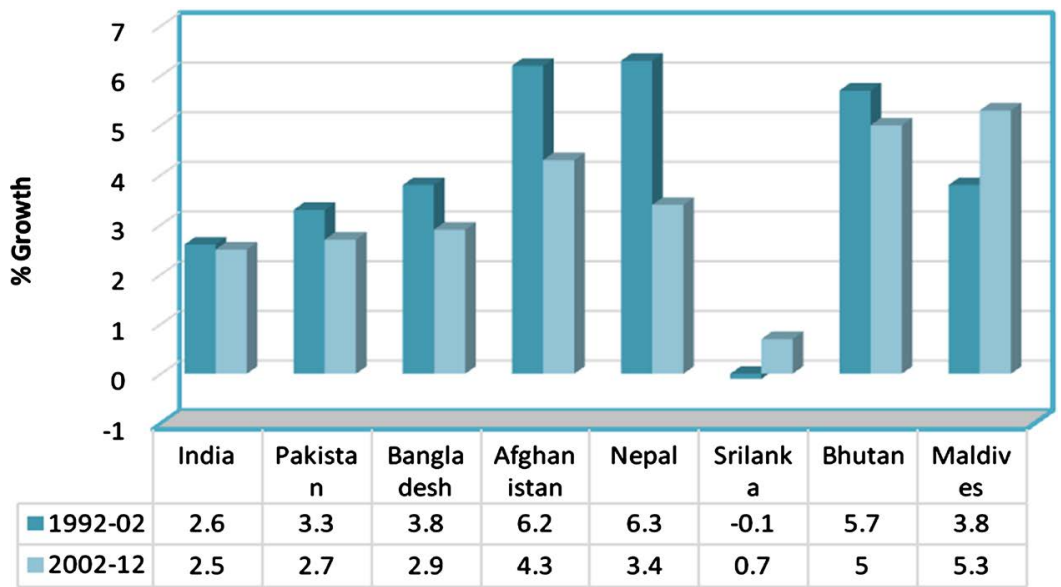

Figure 5. Annual Growth rate (\%) of Urban Population of SAR (Adapted from [6]). 


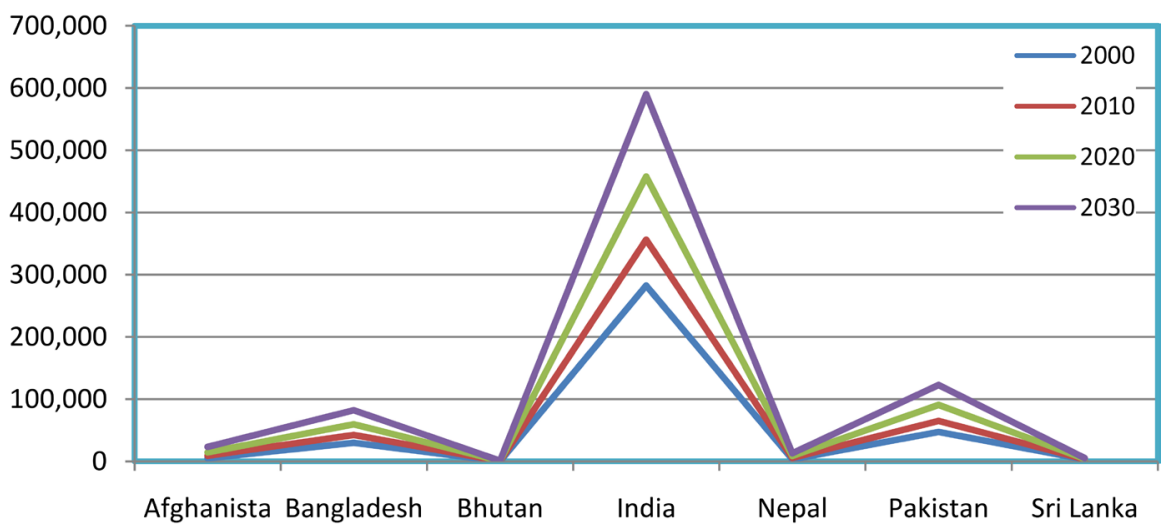

Figure 6. Estimated and projected Population growth in SAR (During 2000 and 2030), Adapted from [6].

Bangladesh has been expected [2]. Earthquake risk assessment requires information about seismic hazard assessment, assessment of building typology and overall exposure of population and assets in hazard prone areas. Seismic Hazards Risk Assessment (SHRA) is primarily based on seismotectonics, past earthquake events, and damage pattern. There is a possibility of higher impacts of future earthquakes in a region whose population growth is at higher side, therefore, earthquake risk management may act as a measure of long-term earthquake impact assessment what need to be adopted.

As mentioned above, several studies made on the Himalaya e.g., [8]-[15] supported the fact that the world's youngest mountain belt, the Himalaya and Hindukush, envelope South Asia all along its northern fringe, from Afghanistan in the west to Bangladesh in the east (Figure 1). It is reported that the Himalaya is still evolving due to northward push of the Indian Plate towards the Eurasian plate. As a result, Himalaya has emerged as the largest active continent-continent collision zone on earth causing numerous major and great earthquakes. Based on the similar processes, the Indian Plate has collided with the Burmese Micro-plate, resulting in deadly earthquakes in the Andaman and Nicobar Islands. The northward convergence of the Indian plate against the Eurasian plate has caused seismicity of central and eastern parts of the Himalaya.

The Indus suture zone is the collisional boundary of the Indian and the Eurasian plates and it marks the beginning of the subduction between Indian subcontinent and Eurasia in early tertiary times. This zone is witnessed by the presence of relict oceanic crust (ophiolite) that separated two continents. With time, the collision boundary shifted southward, and the northern edge of the Indian plate was thrust back onto itself, first along the Main Central Thrust (MCT) and later along the Main Boundary Thrust (MBT), which have also been, recently supported by the estimates made on source parameters. Presently the main tectonic displacement zone lies along the Himalayan Frontal Fault System, which comprises Himalayan Frontal thrust at the edge of the Indo-Gangetic plain, and several anticlines and synclines to the north. Spatial distribution of earthquakes in this region is clustered around the surface traces of the main tectonic discon- 
tinuities such as MCT, MBT and HFT in the Himalayan range, and their tectonic intricacies have also been well documented in the recent publication [16]. The great earthquakes $(M \geq 8)$ occurred in the vicinity of foot hills of the Himalaya in 1905 and 1934, while the eastern syntaxis near the Lohit thrust ruptured in 1950 Assam earthquake. These are the largest earthquakes that occurred on continental thrust faults and are comparable in scale to the great earthquakes of subduction zones [2], which vindicates the alarming scenario of earthquake risks to South Asian countries because the Himalayan arc is associated with a series of interconnecting faults, lineaments, and ridges that are adjudged to be sufficiently capable to either propel seismic wave energy through these faults and lineaments from the Himalayan earthquake source zones to the urban agglomerates of South Asia located in the vicinity of the Himalaya or can arrest the seismic wave energy emanating from the earthquake source zones by the ridges (Figure 1, Figure 7)

Nonetheless, the Himalaya is a source of generating impactful trans-boundary earthquakes because of closer geotectonical inter-connectivity of seismogenic faults that exist beneath Nepal, Bhutan, India, and Pakistan, and even complex seismotectonic settings of Indo-Burmese are found extended towards Bangladesh, and Myanmar. Sometimes earthquakes of different magnitudes also occur within the Indian Plate in the peninsula and in adjoining parts of the Arabian Sea and the Bay of Bengal (Indian Ocean). These are mainly due to localized systems of stress accumulation along mega structures. There are several sub-oceanic faults beneath the Indian Ocean, which have proven track record of impacting coastal regions of SAR, such as Sri Lanka; Maldives; India; Pakistan; and Bangladesh. It is, therefore, seismic risk assessment in the Himalayan region that demands comprehensive analysis of information pertaining to seismic hazards across national boundaries, as these countries share common seismotectonic

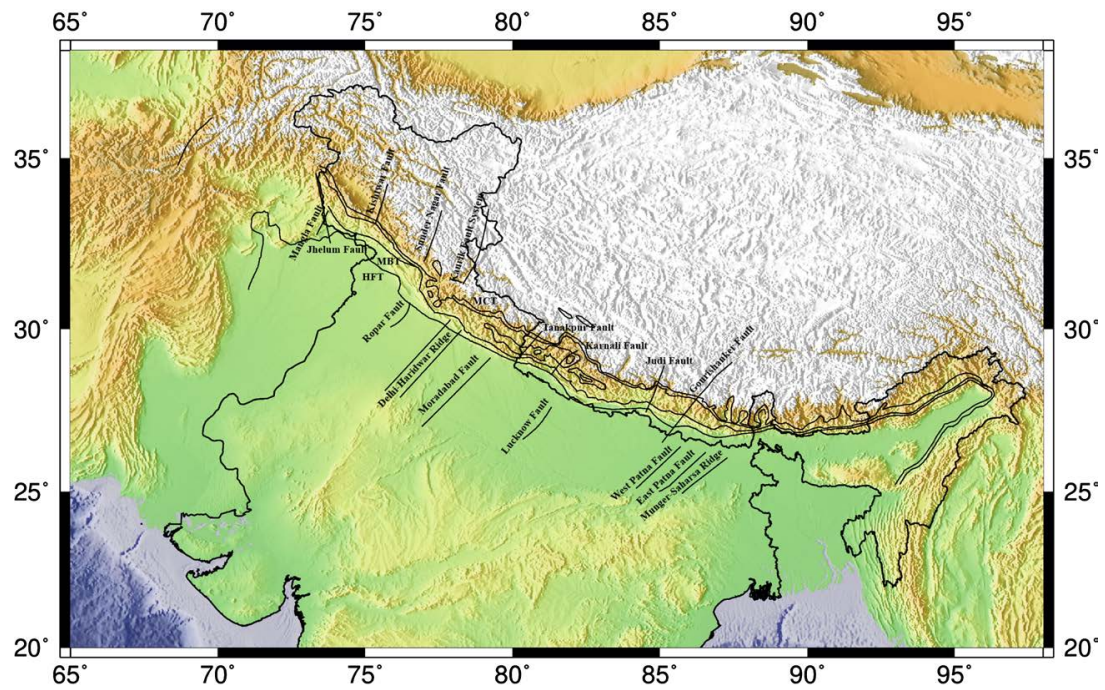

Figure 7. A snap showing the distribution of faults, lineaments, and ridges as the seismic wave energy propagators and arrester of seismic waves originating from the Himalayan earthquakes. 
structures. This has been attempted under Global Seismic Hazard Assessment Program (GSHAP) for the South Asia and country level maps to generate seismic hazard macrozonation maps for the country concerned [13] [14]. The Seismic Hazard Macrozonation map of South Asia based on peak ground acceleration and recurrence time is considered as very qualitative in rendering information related to the specific damage to structures (Figure 8). It is observed that the scale of these maps is not appropriate to get sufficient information in detail for the country. Secondly, these seismic hazard macrozonation of the country in SAR has compromised several pertinent factors that principally govern the degree of damages to property and infrastructures, which again supports the fact that for a given earthquake in a given seismic hazard zone for the given design and typology of buildings with same materials used in constructions, the damages to structures are found, not similar, rather vary differently with varying extent of damages to structures in that specific zone. Such scenario demands different scale of seismic investigation for acquiring detailed data on the subject as requisite for constructing earthquake risk resilient structures of the cities in SAR that can provide much more quantitative information in comparison to that of existing seismic hazard macrozonation. A regional scale seismic hazard map serves limited purpose although it provides very useful broad guidelines on perceived seismic hazard based on seismic and geological data on regional scale. Based on the realistic damage scenario happened during the recent earthquakes that were trans-boundary south Asian earthquakes (e.g., 2004 tsunamigenic earthquake; 2005 Kashmir earthquake; 2011 Sikkim Earthquake; 2015 Nepal earthquake, etc.), it is realized that the seismic hazards needs to be analyzed

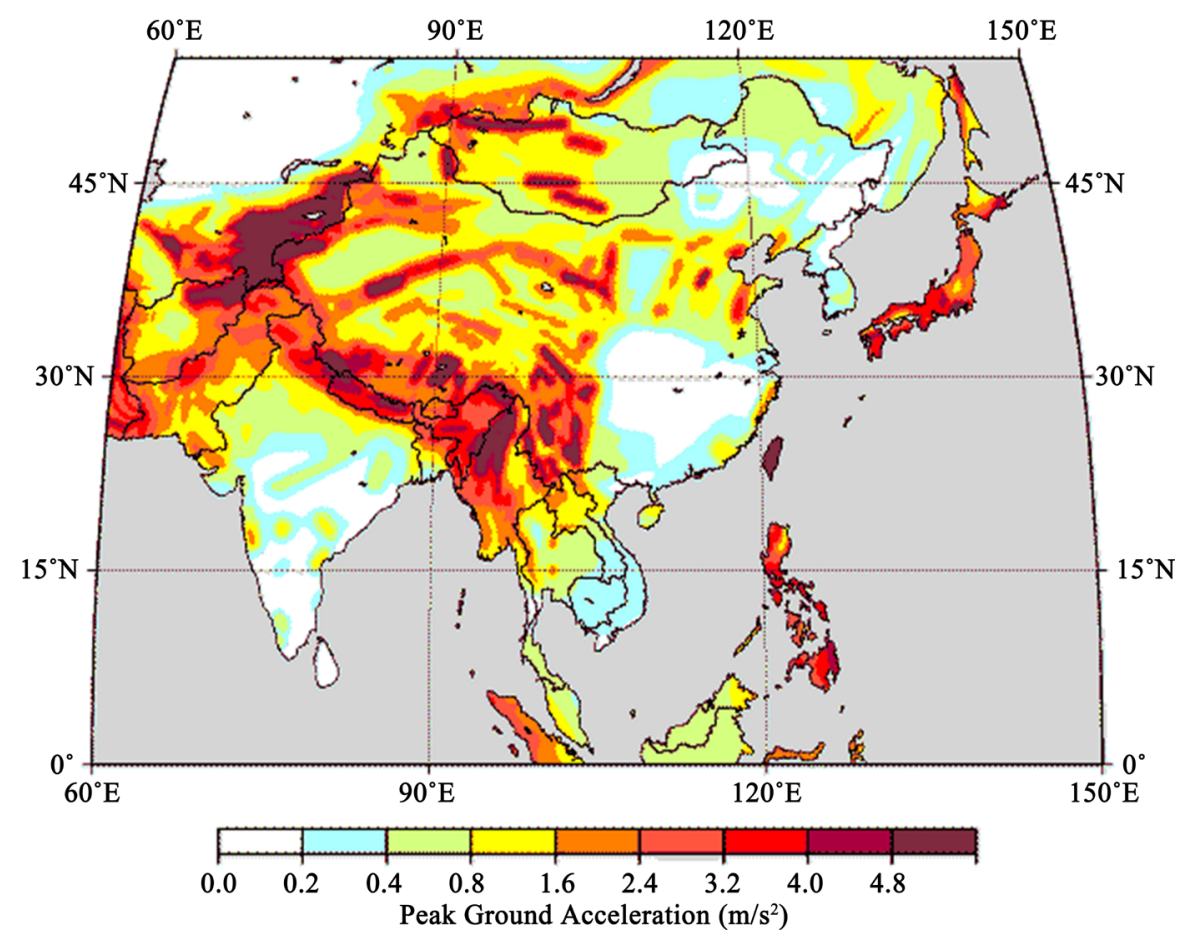

Figure 8. Seismic Macro-hazard Zonation of South Asia Region (SAR). 
for determining impacts of earthquakes in detailed form by considering the local geological and geotechnical and building characteristics and attenuation of the seismic waves in to account at the time of assimilating detailed seismic hazard microzones for the city.

\section{Seismic Hazard Microzonation and South Asian Countries}

As mentioned above, Seismic Hazard Microzonation is one of the powerful methodologies to make a comprehensive quantification of earthquake risks for a specific area of interest, which requires detailed information about several pertinent factors (e.g., geological and seismotectonic set up, topological variation, geomorphological and geophysical variability, and geotechnical characteristics of the sub-surface formations, characteristics of surface accumulating/depositional history, and site specific effects along with the typology and design of the constructions) that need to be estimated through use of geophysical, seismological, and geotechnical tools to understand strong bearing of these factors on dictating the nature and extent of the damage pattern. Seismic Hazard Microzonation is to divide the existing seismic hazard macro-zones into a several smaller zones to investigate physical property variations related to variability of geo-mechanical strengths of sub-surface formations for generating site-specific detailed information at a local-scale for ascertaining the seismic safety of constructions and infrastructures by adopting comprehensive framework (Figure 9) of executing Seismic Hazard Microzonation that directs how to assess the seismic hazard potential for the area. The site specific based information (e.g., spectral amplification; peak frequency, site specific risk index; peak ground acceleration; safety factor of the site, liquefaction, etc.) can be used by the city/town planner for the development of risk resilient infrastructures of the city by highlighting the most and least seismically vulnerable sites of that city. It is so because the impact of earthquake shaking is astonishingly different on the same objects even if these are closely spaced located due to varying geo-mechanical strength of the subsurface formations or foundational materials beneath the objects that get impacted as shown in Figure 10. The city-based seismic microzonation may help identifying the existing structures that may require engineering solutions of retrofitting or which one of the structures require to be demolished for new constructions as per new building design codes.

Realising the importance of earthquake risk assessment for safer structures, various national governments of SAR have initiated studies on seismic microzonation in mostly mega cities of respective countries. Recently, seismic microzonation have been attempted for several mega and capital cities of populous countries of SAR, such as India (e.g., Jabalpur; Delhi; Bangalore; Dehradun; Gauhati; Sikkim; Gandhinagar, Kolkata), Bangladesh (e.g., Dhaka, Sylhet), Pakistan (e.g., Karachi, Islamabad), and Nepal (e.g., Kathmandu, Pokhra) [2] [13] [17]. India has planned to take up comprehensive geophysical and geotechnical based seismic microzonation studies of all her capital/metropolitan cities located 


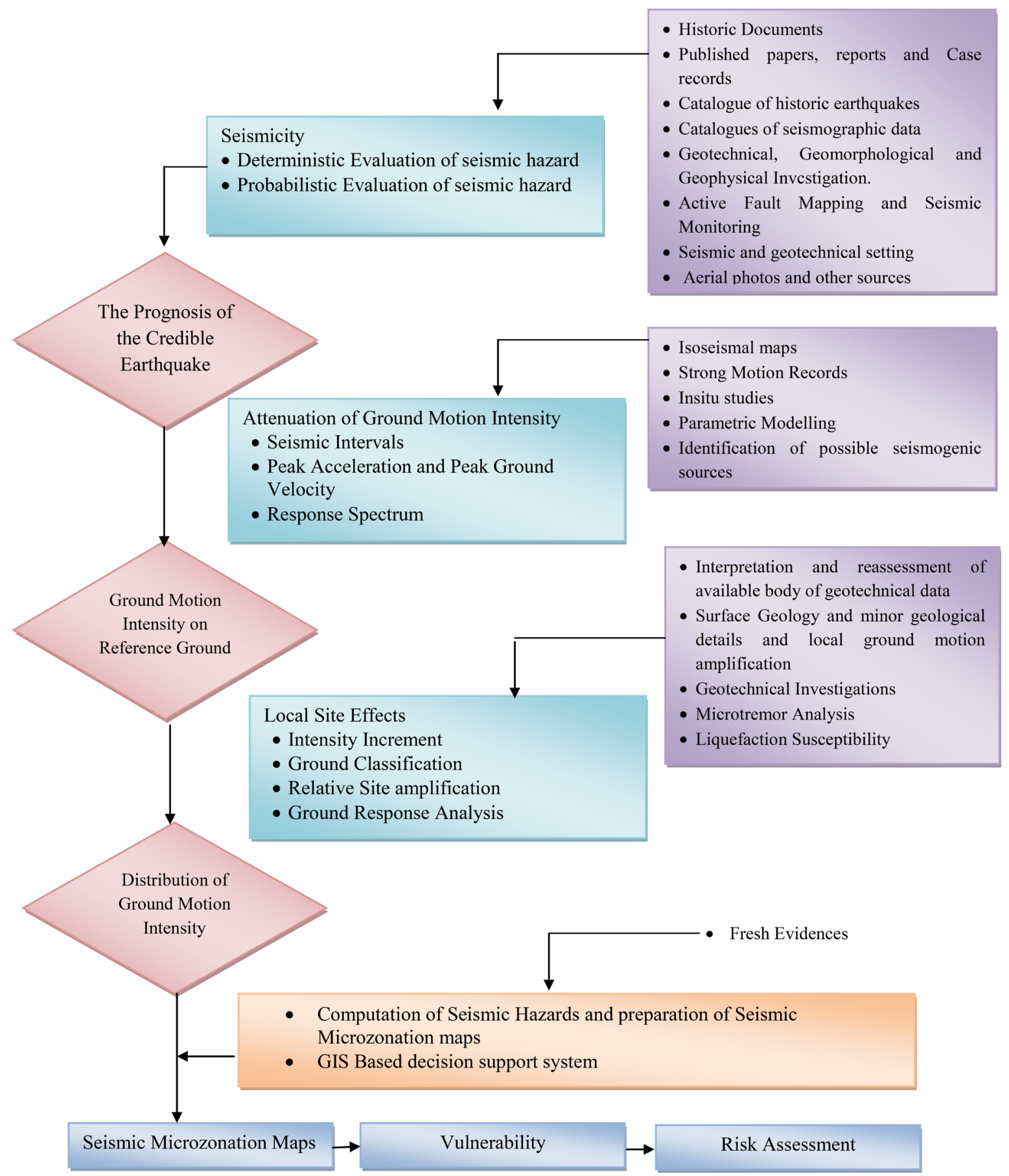

Figure 9. SAARC Seismic Microzonation Framework from seismicity to Risk Assessment developed during 2011 [17].

in seismic zones in a phased manner through increased collaboration among scientific and technical organizations and municipal authorities of the region [2] [18] [19].

It is realised that most of the seismic microzonation programmes more or less similar in approach in terms of the steps to achieve the end result, which can be sketched as under Figure 11, as presented in the workshop among member countries of South Asia Association for Regional Cooperation (SAARC) [17]. 


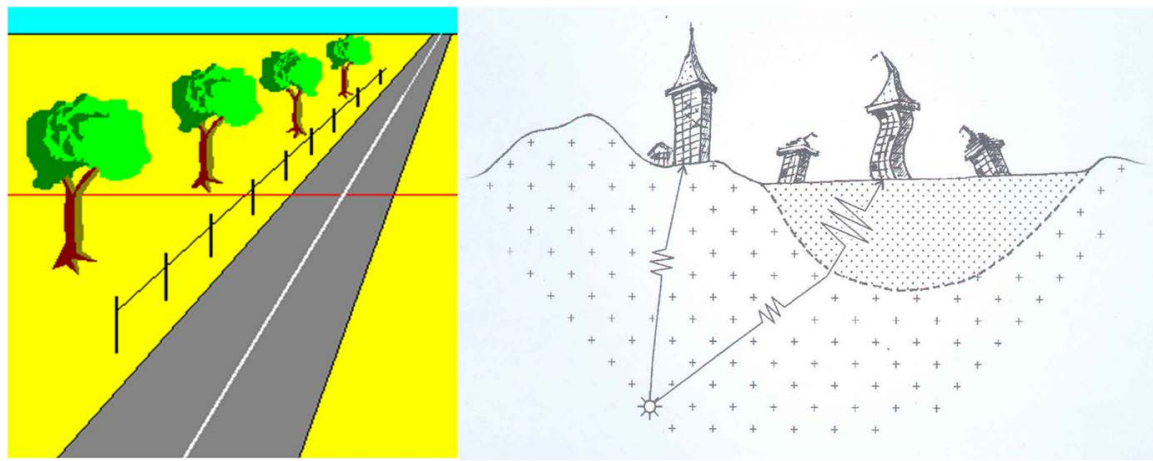

Figure 10. A snap showing varying impact of earthquake shaking on closely spaced objects.

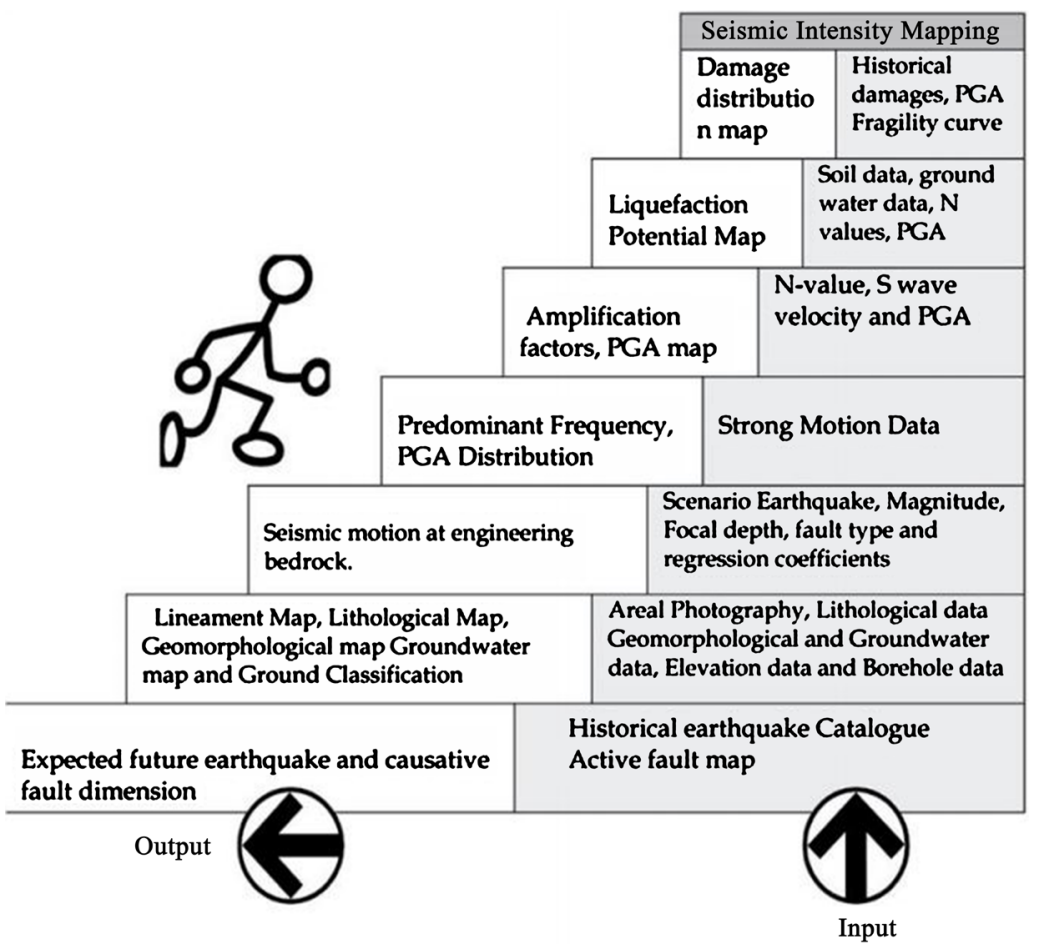

Figure 11. Recommended Seismic Microzonation Action Plan based on [17] [20].

An overview of site investigation methods is given in Figure 12, which has been reported by [17]. [17] discussed the scope that to be considered in planning of a site investigation depends on whether the information is required for preliminary investigation or it is the foremost requisite for finding apt solution to any specific problem. It is argued that geotechnical investigations coupled with laboratory tests of borehole samples become essential for value addition by generating additional data as these are the direct tests for verifying the physical properties of sub-surface materials that have been determined independently using geophysical and seismological methods. In order to get detailed information on engineering bed layers and about the overlying soil layer, deployment of geophysical techniques and penetration tests are adjudged to be pre-requisite conditions, which can be judiciously corroborated by drilling, undisturbed 


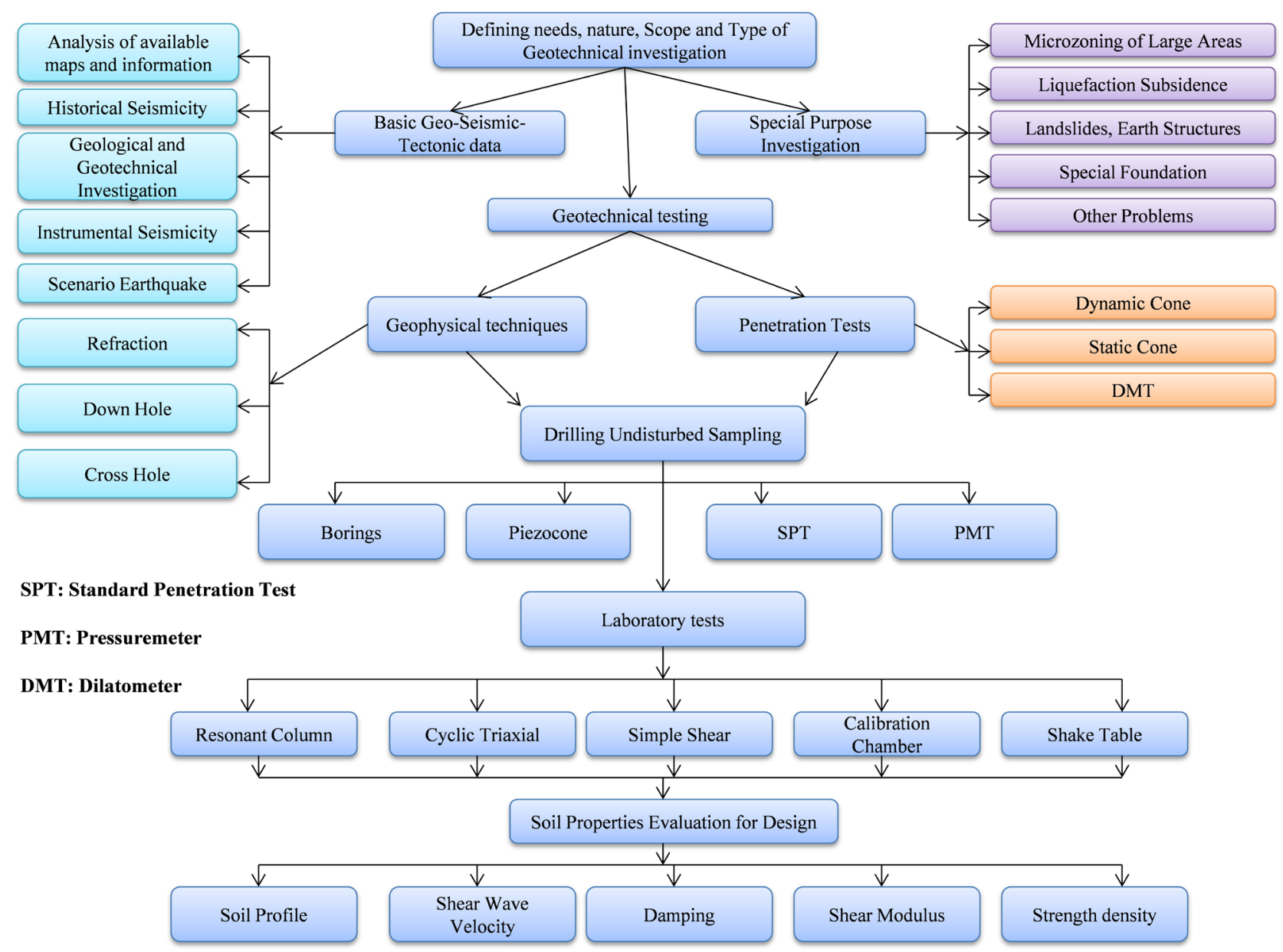

Figure 12. An overview of Site Investigation Methods applied by SAARC Member states since 2011. SPT, DMT and PMT are abbreviations of Standard Penetration Test; Dilatometer; and Pressuremeter, respectively used for geotechnical investigations of soil [17].

sampling and laboratory testing consisted of resonant column tests, cyclic triaxial test, simple shear tests, calibration chamber tests and shake table tests. Centrifuge testing also has its own place depending upon the nature of problem to be resolved.

\section{Levels of Seismic Hazard Microzonation}

Depending upon the scale of investigation, the technical committee of the international society of soil mechanics and foundation engineering (ISSMFE) in the year 1993 has recommended three levels of microzonation, such as, Grade 1: General Zonation (1:50,000 to 1:100,000); Grade 2: Detailed Zonation (1:10,000 to 1:100,000) and Grade 3: Rigorous Zonation (1:5000 to 1:25,000) as shown in Figure 13. The recommendation essentially meant making a beginning with relatively small scale mapping and move on higher levels of microzonation by obtaining added quality inputs that could justify large scale mapping [17]. It is observed that extreme sensitivity of sub-surface foundational materials to earthquake shaking demands even more detail and too precise investigations of physical properties contrasts of the materials at the smallest possible scale to ascertain the 
degree of earthquake shakings and its impact on the closely spaced built structures and infrastructural facilities.

In a brainstorming session organized by [17] unravelled the fact that it is not always necessary to think of varying scale of mapping. There are location specific seismic microzonation programmes in which scale of mapping is not altered (1:5000 to $1: 25,000)$ to all three-levels of zonations but seismic zonation grade is steadily improved with the influx of more data as the investigations unfold. This scheme of operation is illustrated in Figure 14. The proedure undergoes the point that seismic microzonation is always a work in progress and sustained effort to upgrade the attempts through investigation, value addition and falsification (as opposed to verification) is necessary to raise its degree of reliability. In all seismic microzonation mapping programmes, the first effort is always directed toward production of the maps of peak ground acceleration at the bedrock level. The next setup is then to produce ground motion amplification maps.

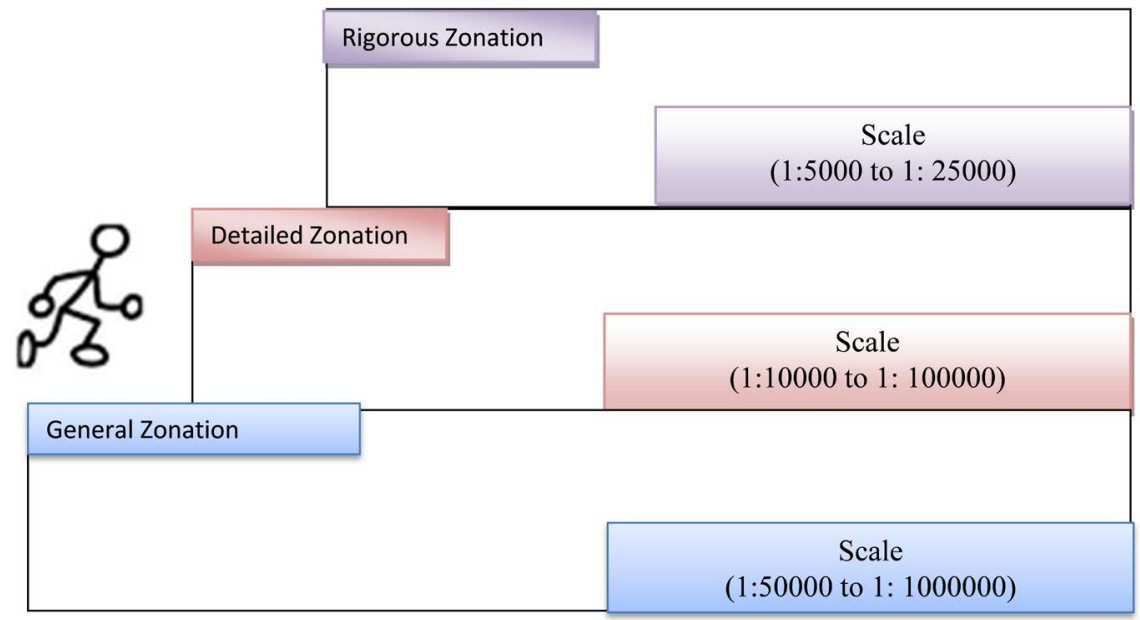

Figure 13. Three Grades of Seismic Microzonation recommended by the Technical Committee of the International Society of Soil Mechanics and Foundation Engineering (ISSMFE) [17].

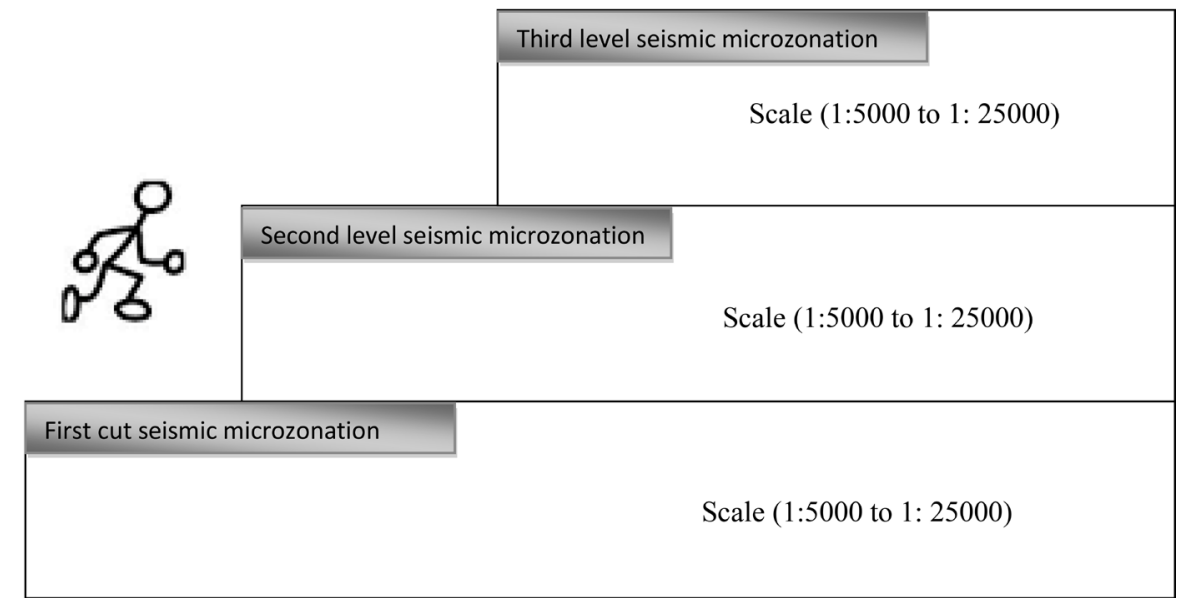

Figure 14. Improved levels of Seismic Microzonation at the same scale of mapping with improved data density [17]. 
Here again, it is often more practical to first think in terms of first-cut exercise to be upgraded in appropriate number of steps [17].

\section{Country Specific Seismic Microzonation of SAR}

As mentioned above, seismic risk assessment of all SAARC member states realised the need because of the excessive vulnerability to earthquake risks and earthquake induced disaster events, such as tsunami, landslide, and glacial lake outburst flooding (GLOF) under climate change conditions in the region. Different countries of South Asia region (SAR) have already adopted different yard sticks of earthquake risk assessment and conduction of seismic microzonation studies at varying scale of investigation. Here, we describe some of cities of SAR as their case histories of seismic microzonation for the respective country, which need to be understood before initiating the advanced stage of seismic microzonation.

\subsection{Afghanistan}

Afghanistan is located in the tectonically active southern part of the Eurasian plate. The northward motion of the Indian plate and Arabian plate has given rise to mountains and numerous earthquakes in Afghanistan. The distribution of earthquake epicenters in Afghanistan reveals that the northern and eastern parts of the country are more vulnerable compared to the southern Afghanistan that lies on the un-deformed Eurasian plate [2]. It has also reported that the seismic activity is the result of collision of Eurasian plate with the Arabian plate to the south at about $30 \mathrm{~mm} / \mathrm{year}$, and transgression with the Indian plate to the south east at about $40 \mathrm{~mm} /$ year. Revised estimates of Arabia-Eurasia convergence rates based on recent GPS data suggest that the Arabia's collision rate with Eurasia have reduced to $22 \mathrm{~mm} /$ year. The seismicity in the region is not distributed uniformly. Within the wide deforming belts lie areas of little known seismicity during the $20^{\text {th }}$ century, such as for example, western and central Afghanistan. It has been reported that Kabul has been estimated to have the highest seismic hazard due its proximity with the active Chaman Fault. The western Afghanistan has low seismic hazard as compared to the east [2]. However, Herat, on the western part of the country, has relatively higher hazard due to its proximity to Hari Rud fault while Kandhar on the eastern part of the country has low seismic hazard as it is located away from the Chaman fault. Earthquakes in the M7.0 range have been experienced in parts of the country. The northeast region is associated with high hazards, where most of the shallow as well as deep earthquakes are located at the intersection of Chaman and other fault systems of the region [2].

Since landslide hazard co-exists with earthquake hazards, seismic microzonation programmes in Afghanistan attempted to integrate hazard mapping with seismic microzonation [17]. The ground-motion distribution in Afghanistan is high to moderate and moderate to low from the northeast to the southwest. Different researchers estimated PGA values for entire Afghanistan (Figure 15 \& Figure 16) 


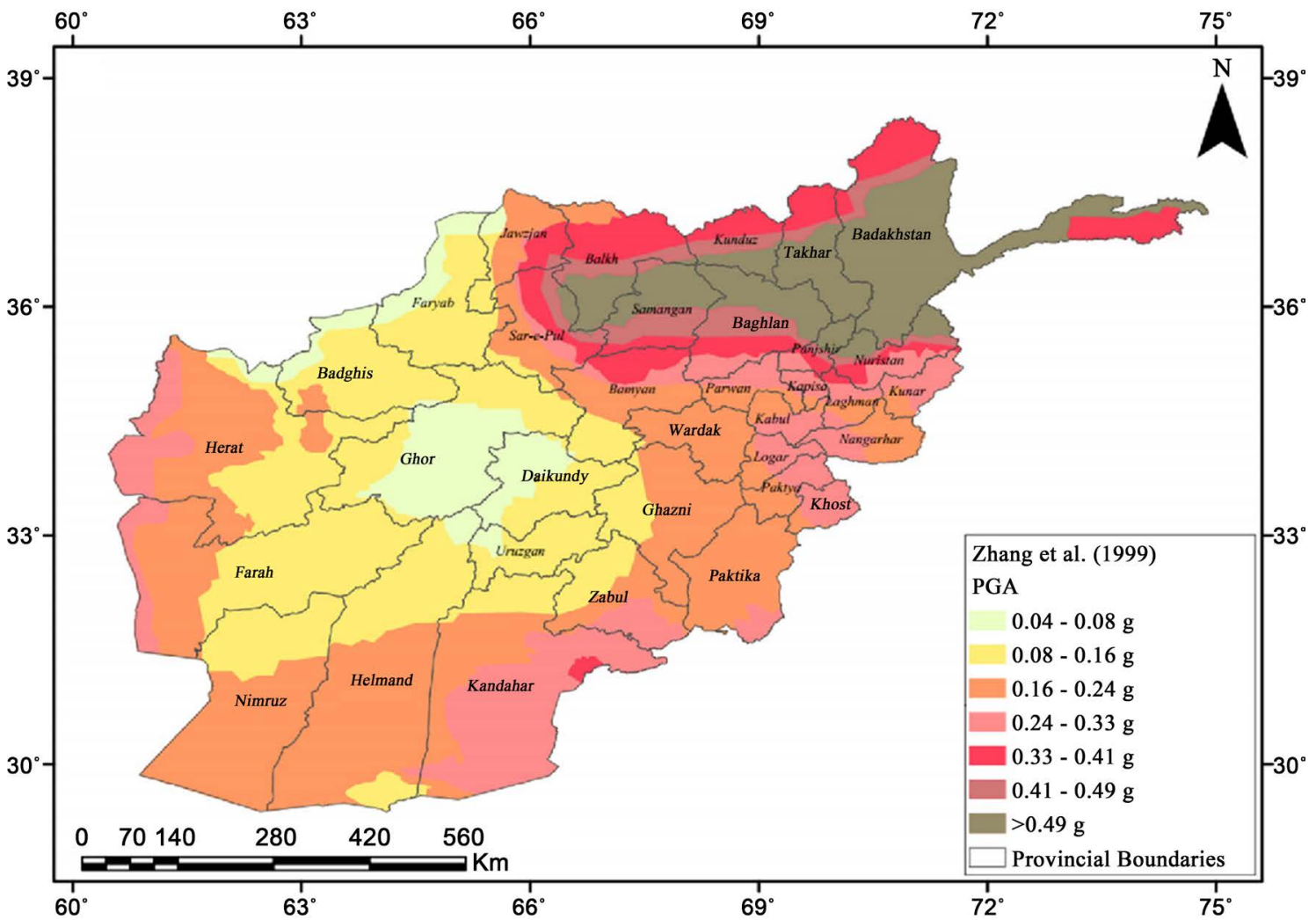

Figure 15. PGA value contour map for Afghanistan [21].

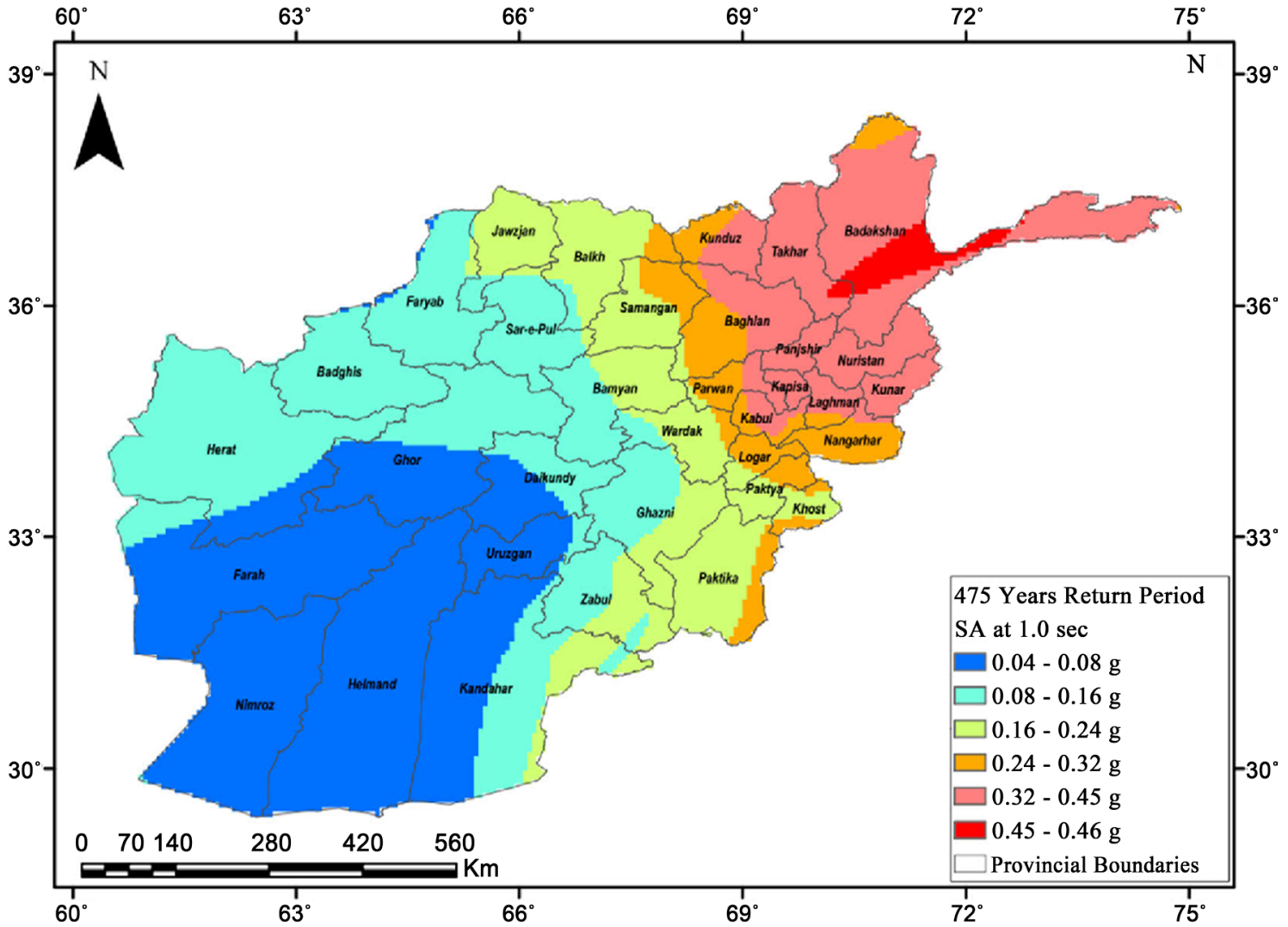

Figure 16. PGA value contour map for a 475-year return period [22]. 
to assess the extent of earthquake risks of the country [21] [22]. The PGA ranges from $0.06 \mathrm{~g}$ to $0.66 \mathrm{~g}$ for return periods of 475 years. Among the provinces, Badakhshan is expected to experience the highest PGA value of $0.656 \mathrm{~g}$, while Khunduz and Kabul provinces are expected to experience PGA values of $0.540 \mathrm{~g}$ and $0.480 \mathrm{~g}$, respectively, corresponding to a 475-year return period [17].

The northeast to southeast region of Afghanistan exhibits the highest ground motions compared to the rest of Afghanistan; so, the threat to human lives and infrastructure is very high in this region. Therefore, seismic risk mitigation measures should be taken to minimize the seismic risk and losses. The values obtained in the current study are generally in agreement with the regional PSHA study of Zhang et al. (1999) (Figure 15 \& Figure 16) carried out under the network of the Global Seismic Hazard Program (1992-1999). It has also been validated that ground-motion values obtained in this study match well with the ground-motion values across the border for Pakistan, Uzbekistan and Turkmenistan, except for the bordering regions of Iran, where the difference is comparatively higher. Generally, the results of the study are consistent with the bordering countries [17].

\subsection{Bangladesh}

It has been reported that Bangladesh and the north-eastern Indian states have long been one of the seismically active regions of the world, and have experienced numerous large earthquakes during the past 200 years. There are several seismogenic faults (e.g., Assam Fault Zone; Tripura Fault Zone; Sub-Dauki Fault Zone; and Bogra Fault zone) having credentials of generating earthquakes of magnitude varying from M 7.0 to M 7.5 that can affect the extent of earthquake shaking that have severe impacts on structures. The catastrophic earthquakes of 1762 and 1782 are believed to have been partially responsible for the diversion of the main flow of the old Brahmaputra river from the west to present Jamuna river and main flow of the Arial Khan river to the present Padma Channel [2]. Seven major earthquakes $(M>7)$ have affected Bangladesh during the last 150 years from $10^{\text {th }}$ January, 1869 Cachar earthquake (M 7.5) to $15^{\text {th }}$ August 1950 Assam earthquake (M 8.5) with epicentre distances varying from $150 \mathrm{~km}$ to 780 $\mathrm{km}$ [17].

It is also reported that only two earthquakes, namely those of 1885 and 1918 had their epicenters within Bangladesh. It has been reported that diversion of the old Brahmaputra River from the west to the present Yamuna River as well as the diversion of the main stream of the Arial Khan River to the present Padma River is believed to have been facilitated by the devastating earthquakes of 1762 and 1782 [17]. All these observations suggest the high seismic risk of Bangladesh. It is reported that Bangladesh Meteorological Department began the process of preparing a seismic zonation map which got first adopted in 1972. The country was divided into four instead of the earlier three zones, with a seismic factor assigned to each. The zone of the highest severity was associated with the seismic 
factor in the range $0.2 \mathrm{~g}$ to $0.1 \mathrm{~g}$ and the least severe zone got associated with seismic factor of less than $0.05 \mathrm{~g}$. The two intermediate zones were assigned seismic factors of $\mathrm{g} / 10$ to $\mathrm{g} / 15$, and $\mathrm{g} / 15$ to $\mathrm{g} / 20$ respectively.

The first seismic hazard map of Bangladesh (Figure 17) was compiled by the Geological Survey of India in 1935. The meteorological department prepared a hazard map in the sixties that was adopted in 1972. The entire country was divided into four zones: major damage $(10 \%-20 \% \mathrm{~g})$, moderate damage $(6.7 \%-10 \% \mathrm{~g})$, minor damage $(5 \%-6.7 \% \mathrm{~g})$ and negligible damage $(<5 \% \mathrm{~g})$. The map was further revised in 1979 by the Geological Survey of Bangladesh and an outline of earthquake resistant design was also prepared. This map and the outline formed the basis for designing most of the important structures built during the next 20 years [2].

In 1992, the Government appointed a team of consultants to prepare a National Building Code for Bangladesh. As part of this study, a comprehensive review of present data has been undertaken and a revised seismic hazard map has been compiled. The results have been incorporated in the Bangladesh National Building Code. The hazard map retains the major features of the earlier maps and divides the country into three zones. The zone of highest hazard (Zone 3) includes the north and north-eastern parts, the zone 2 covers the central part and Zone 1 covers the remaining south-western part of the country [2]. It is
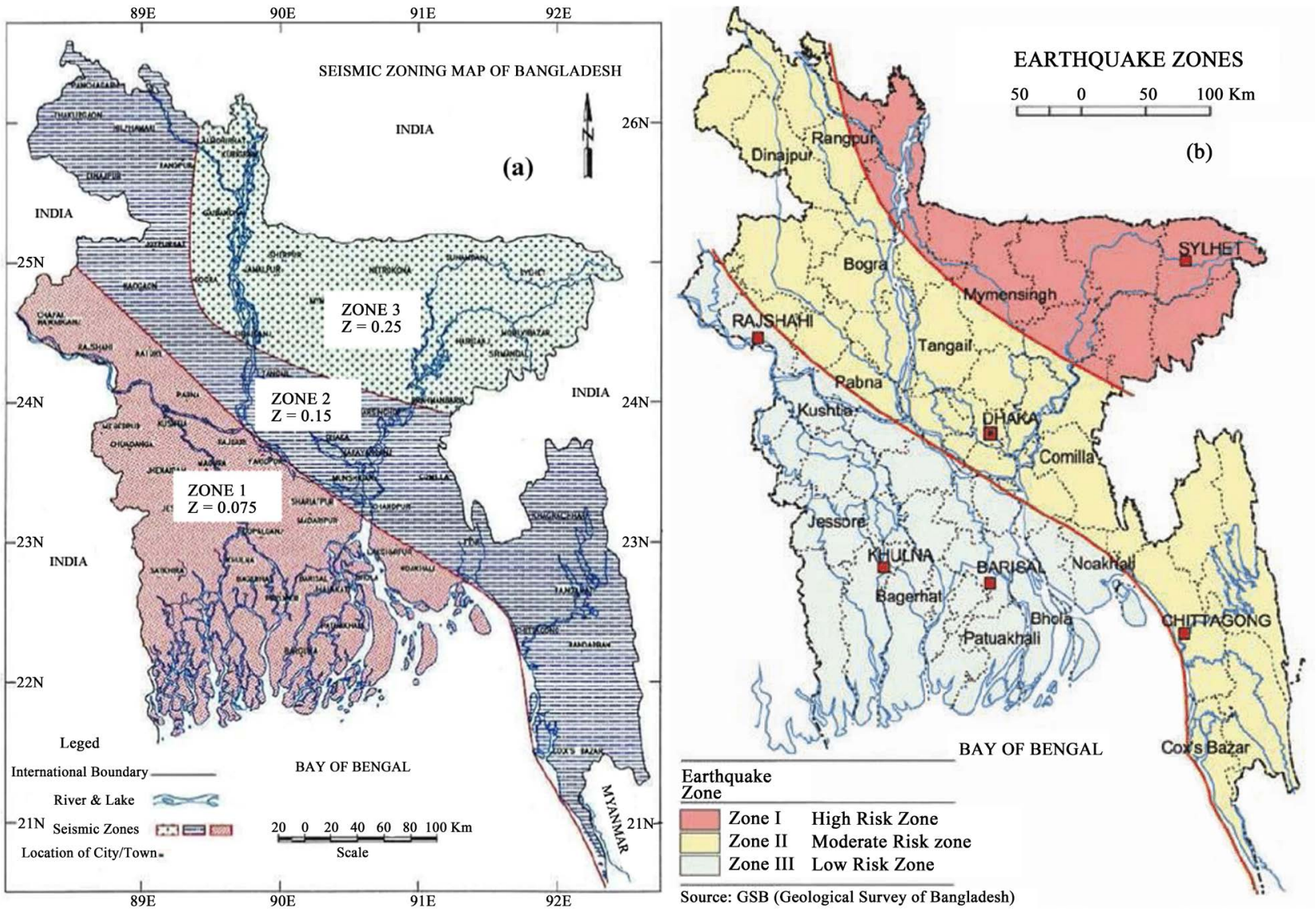

Figure 17. Seismic Hazard Map of Bangladesh: (a) Old [by Bangladesh National Building Codes (BNBC)]; and (b) Updated [by Geological Survey of Bangladesh (GSB)] Version [2]. 
found that GSHAP has taken extra effort to compile data for Bangladesh that lies in a region of low to high seismic hazard that increases in the northern and eastern parts of the country. Historically, earthquakes in the M 6.0 - 7.0 range have been experienced in Chittagong, Dhaka and Sylhet divisions while events in the M 5.0 - 6.0 range have been experienced in Khulna and Rajshahi divisions. However, the hazard maps (Figure 17 \& Figure 18), do not include the liquefaction effect, which may increase the damage potential in low lying areas with soft sediments and shallow groundwater level [2].

GSHAP deduced the fact that Dhaka, Chittagong and Sylhet have been experiencing earthquakes in the magnitude range M 6 - 7. Population scenarios are dramatically different now and therefore the seismic risks are much higher. An earthquake Risk and Vulnerability study of Dhaka city suggest that in the event of an earthquake leading to intensity VIII damage, about $13.4 \%$ houses may be severely damaged. The percentage can be much higher in case of Sutrajpur and somewhat lesser in the case of west Dhanmondi [17], suggesting the need of

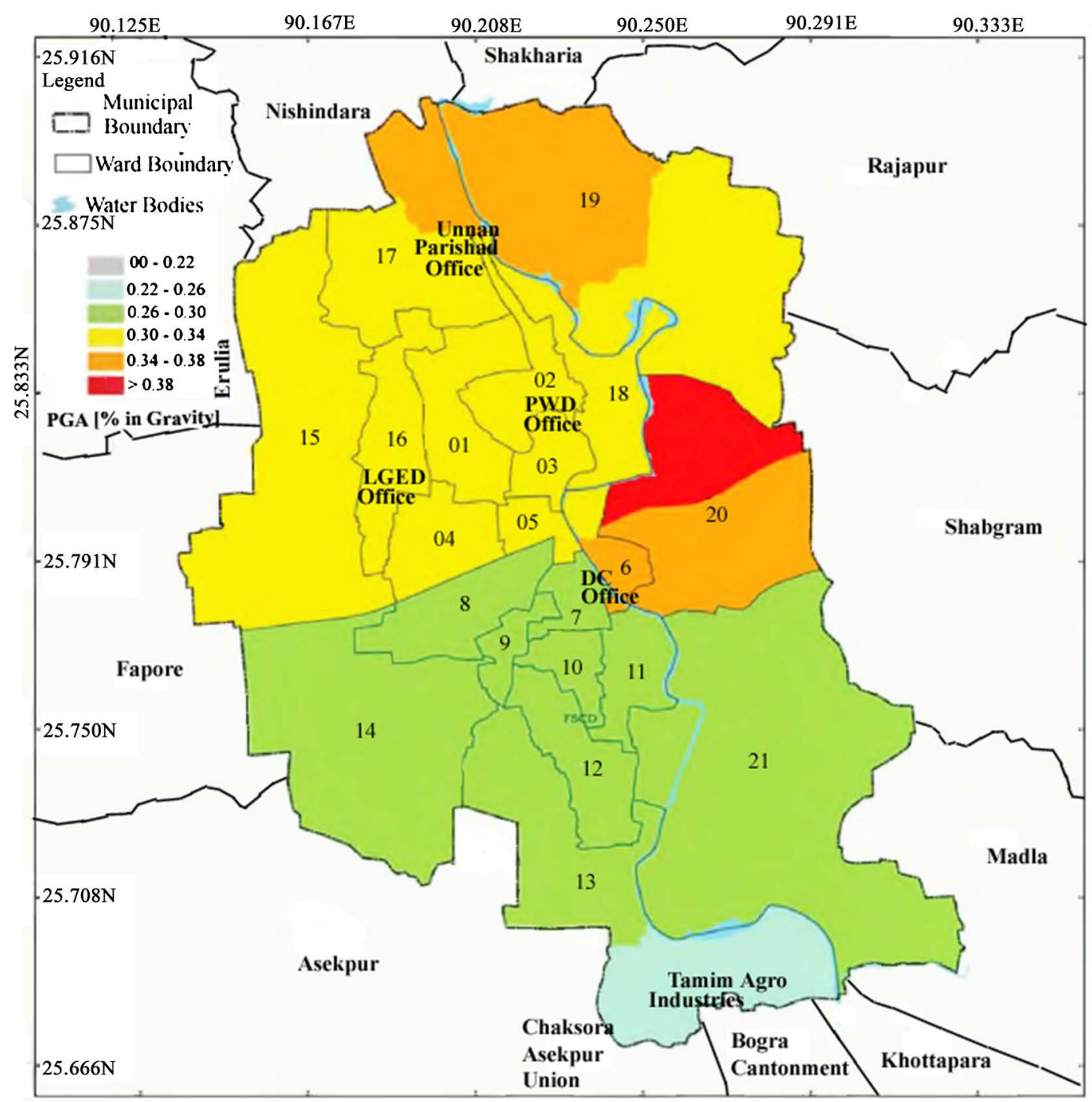

Figure 18. Map showing the distribution of PGA value for the city of Dhaka [2]. 
conducting comprehensive seismic hazard zonation map for mega cities of Bangladesh. Dhaka, on the world map of the most populous cities is located in a seismic zone with estimated peak ground acceleration approaching $0.15 \mathrm{~g}$. Added seismic hazard comes from the ground amplification of earthquake motion imminent because of the nature of geological strata and spread of filled up areas. Interestingly, Bangladesh National Building Code (1993) which classifies soil into four categories S1, S2, S3, S4 offers design response spectra for first three soil types and does not offer any response spectra for soil type S4. This underscores the need for seismic microzonation to facilitate site specific evaluation of seismic hazard. Response spectra for soil types S2 and S3 at different localities of Dhaka city have been assimilated for the city of Dhaka and comparison with design response spectrum helped in generating the Bangladesh National Building Code (BNBC).

It has also been reported that data collected from 75 boreholes from 35 sites to classify sites as soil types S2, S3 and S4 based on the BNBC have also been examined. Comparision of numerical results with the BNBC design response spectrum for soil type S2 and for soil type S3 was made. Results suggested some increase in peak spectral acceleration values in the existing design response spectra [17]. Apart from the city of Dhaka and Chittagong, some of other cities of Bangladesh are worthy of consideration for conducting seismic microzonation studies of cities, like Sylhet, Mymensingh, Sirajpur-Bogra, Rangpur, and Balisera.

\subsection{Bhutan}

The mountainous Himalayan state of Bhutan with a population of 700,000 is situated in one of the seismically most active zones of the world encompassing Lesser and Central Himalayan zone. Recent study suggested that an earthquake of magnitude 8.1 to 8.3 may hit the $2000 \mathrm{~km}$ long seismic belt very soon because of compounding strains and seismic silence for 500 years [13]. In the year 2005, Motegi, working with Geological Survey of Bhutan opined that seismically active zone had shifted to about $180 \mathrm{~km}$ from the Himalayan foothills to the Shillong plateau. With the plate moving away, Bhutan has become safer, in his view. He further reported that the probability of a major earthquake (M $7-8)$ was minimal. The adjoining parts of India have been classified as very high hazard that lies in zone V and IV of the seismic zoning map of India. The major tectonic discontinuities present in the Bhutan Himalaya are Main Frontal Thrust, Main Boundary Thrust and Main Central Thrust (Thimphu Thrust). About 46 seismic events have been recorded within the territory of Bhutan during 1928 to 1998. The effect of some of the great earthquakes of the Indian sub-continent like 1897 (Shillong), 1934 (India-Nepal) and 1950 (Assam) have jolted Bhutan as their epicenters lie within a distance of $500 \mathrm{~km}$ from Bhutan [2].

In recent years, Thimphu, Paro and Phuentsholing have witnessed the effects of significant earthquakes since 1980 (M 6.1) and most recently in the year 2011 Sikkim earthquake (M 6.9) [2]. Preliminary Seismic Hazard Zonation of Bhutan 
was carried out by Geological Survey of India. Bhutan was classified into four seismic hazard zones viz. very high, high, moderate and low. According to GSHAP data, Bhutan lies in a region of high to very high seismic hazard that increases towards eastern parts of the country. It has been reported that more systematic and detailed exercise considering the past seismicity, seismotectonics, and active faults in the country and surrounding region of Bhutan is required for a realistic Seismic Hazard Assessment of the country [2]. The most vulnerable region in Bhutan is the Thimphu valley with very high population density and high stage of development. Realizing this, Standards and Quality Control Authority, Royal Government of Bhutan, initiated the "Thimphu Valley Earthquake Risk Management Project" (TVERMP) with support from UNDP. The project developed an earthquake risk scenario for the Thimphu valley using RADIUS (Risk Assessment Tool for Diagnosis Urban Areas against Seismic Disasters); conducted vulnerability assessment of 15 critical buildings and produced awareness materials on earthquake resistant construction technology and good practices [2]. Bhutan was without its own Seismic Zonation Map. It has also been reported that the whole of Bhutan was therefore believed to be in the Seismic Zone V according to the Indian Seismic Hazard Zonation Map. Some seismologists placed western Bhutan in Zone IV and eastern Bhutan in Zone V. A seismic hazard map of Bhutan has been prepared by the Indian Institute of Technology, Roorkee. It divides Bhutan into seismic zones of very high, high, moderate and low hazard. Haa, Chukha, Trashiang, Mongar, Ihuentse, Trashiyangste and the southern Dzongkhags are placed in high to very high hazard zone. Thimpu, Paro, Punakha, Bumthang and Trongsa valleys fall in moderate to low hazard zones [17]. Despite the macro-sesimic hazard zonation map of Bhutan, cities of Bhutan still lack of comprehensive seismic hazard microzonation maps. It has been reported that nearly $60 \%$ of the older construction in Thimpu is earthquake-unsafe. Naturally seismic microzonation will promote safer future construction and timely retrofitting by realistic assessment of seismic hazard and risk [17].

\subsection{India}

India is the place associated with all types of earthquakes, occurring in different tectonic blocks of India and its adjoining region, such as the Himalayan collisional belt; the Andaman-Nicobar subduction zone; NE-India and Indo-Burmese region; the intra-plate region of Peninsular; and Reservoir induced earthquake zones, which witnessed a series of moderate, strong to several great earthquakes that caused enumerable losses to properties and people. Consequently, shaking of these earthquakes has strong impacts on buildings/structures/infrastructures of India and its surroundings. Based on such realistic disastrous scenario due to earthquake, Geological Survey of India compiled the first national seismic hazard map of India in 1935 [2]. The revised maps more closely associated with the known seismotectonic features without sacrificing the information obtained 
from earthquakes and from theoretical ground motion attenuation relationships and the most recent Seismic Hazard Zoning map of India (IS 1893:2002) (Figure 19), the Indian landmass has broadly been classified into four distinct seismic zones, viz., Zone-II (MSK Intensity-VI); Zone-III (MSK Intensity-VII); Zone-IV (MSK Intensity-VIII); and Zone-V (MSK Intensity-IX), based on their liability to different degree of seismic intensity GSI prepared the hazard map for reference [2]. It is important to note that each of the above-mentioned zones is reasonably expected to have earthquake shaking of more or less same maximum intensity in future. It is, however, the maximum seismic ground acceleration in each zone cannot be presently predicted with accuracy either on a deterministic or on a probabilistic basis. The basic zone factors included in the code are reasonable estimates of effective PGA for the design of various structures. In accordance to GSHAP programme, PGA was also estimated and it shows good correspondence with existing Seismic Hazards of the region (Figure 19). The regions away from the Himalayas and other inter-plate boundaries were previously considered to be relatively safe from the impacts of devastating earthquakes [12] [22] [23]. However, several researchers demonstrated the seismogenic and defo-

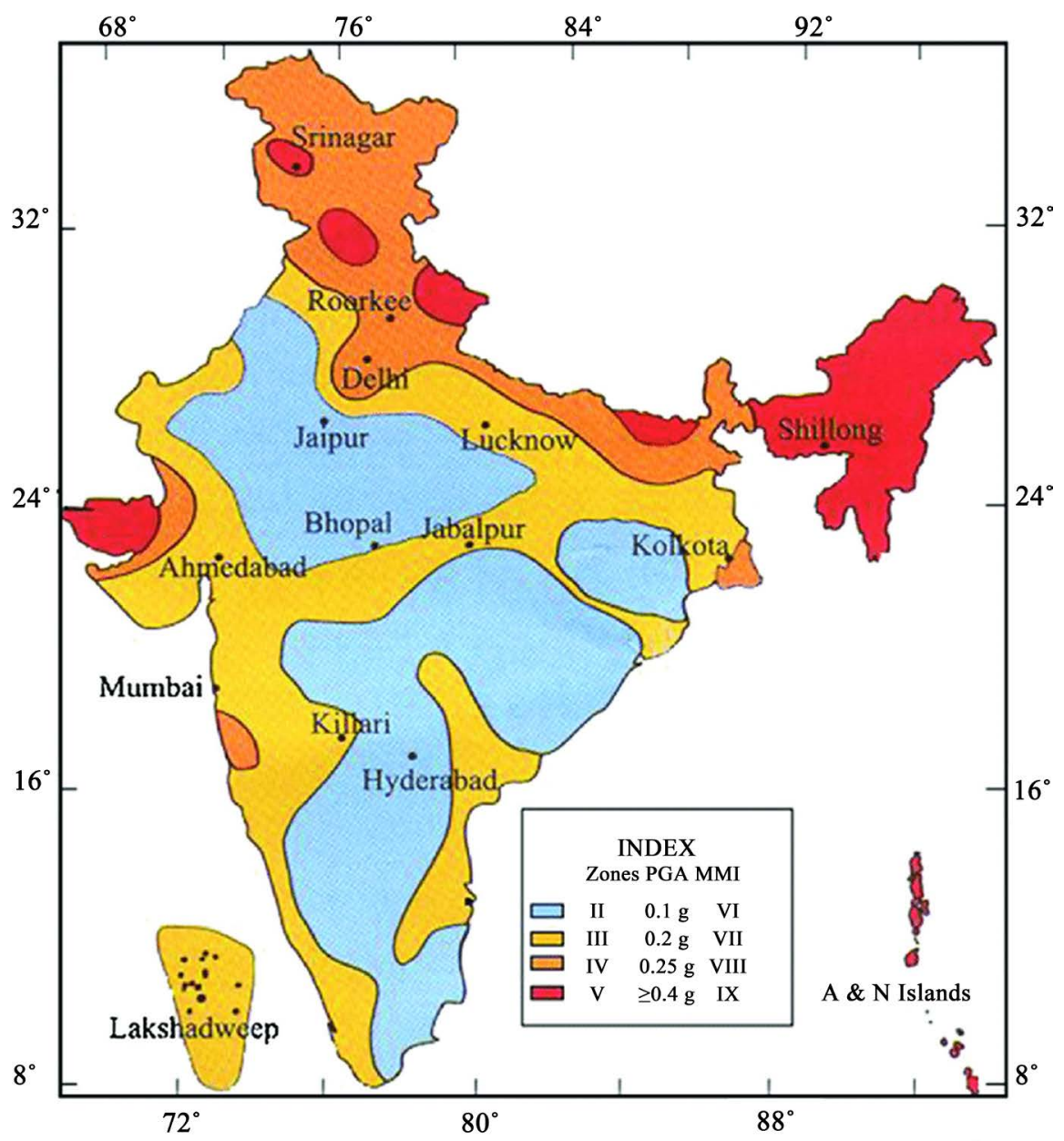

Figure 19. Seismic hazard zonation map of India (After Beuro of Indian Standard (BIS1893-2002). 
rmational regime of earthquake prone zones, such as the Koyna earthquake of 1967; the Latur earthquake of 1993; the 1997 Jabalpur earthquake, and the 2001 Bhuj earthquake, and impacts of several trans-boundary earthquakes (the 2004 north Sumatra-Andaman earthquake; 2005 Kashmir earthquake; the 2011 Sikkim earthquake, and the 2015 Nepal earthquake) [1] [24] [25] made understand that there are several parameters, which have been compromised in estimating seismic hazard macrozonation map for specific earthquake [26] [27] [28] [29]. Seismic Macrohazard map of India (Figure 19 \& Figure 20) is shown in sense that in-situ material heterogeneity and associated site specific seismic attenuation law has not been considered at the time of preparing the map. It is, therefore needs rigorous investigations at smaller scale to generate information through seismic microzonation what India has been doing under the flagship project of Ministry of Earth Sciences (MoES) since recent years and is very much ahead among other countries of SAR by involving herself for investigating comprehensive seismic microzonation of several capital/strategic cities in India in a mission mode [30] [31] [32] in accordance to the approved guidelines described in the "Handbook of Seismic Microzonation"; and "Manual for Seismic Microzonation" developed by the Ministry of Earth Sciences (MoES), a nodal ministry for completing the job of seismic microzonation of cities in India [19] [32] [33]

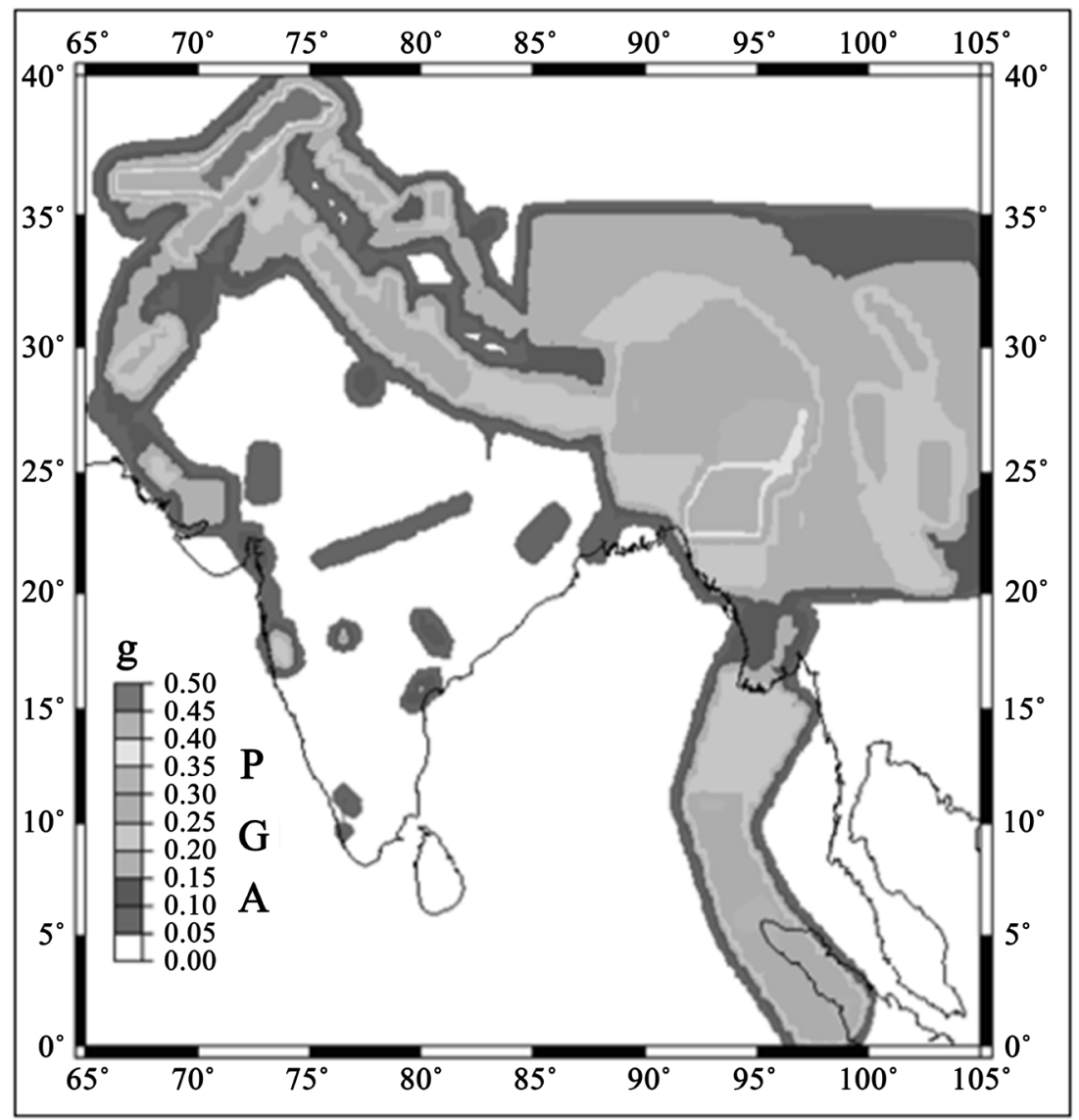

Figure 20. Seismic hazard map of India and adjoining regions, prepared under GSHAP programme. 
[34]. Accordingly, India has completed comprehensive microzonation for several cities (e.g., Bangalore; Delhi-NCR; Dehradun; Jabalpur; Gandhinagar, Kolkata; Sikkim), and several other cities (e.g., Bhubaneshwar; Chennai; Coimbatore; Mangalore) are under investigation, while cities, such as Agra, Amritsar, Dhanbad, Kanpur, Lucknow, Meerut, Patna, Varanasi are in process of commencement of the study.

In assessing the seismic hazard of any urban centre, ambient noise measurements are quite popular in estimating the amplification and the dominant frequencies of soil column using experimental microtremor method. The method requires a seismic broad band station with three components for estimating the site response using Nakamura technique where the resonance frequency is obtained by evaluating the horizontal to vertical spectral ratios. The main consideration of this technique is the micro tremors which are primarily composed of Rayleigh waves, produced by local sources. These waves propagate in a surface layer over a half space, considering the motion at the interface of the surface layer and half space is not affected by the source effect and the horizontal and vertical motion at this interface are approximately equal. Site response studies mainly deal with the determination of peak frequency (PF) of soft soil, amplification and the nature of response curve defines the transfer function at the site which forms an important input for evaluating and characterizing the ground motion for seismic hazard quantification. But microtremor studies show that the predominant frequency of Bangalore soil varies from $1.5 \mathrm{~Hz}$ to $12 \mathrm{~Hz}$ for the corresponding amplification values (Figure 21(a) \& Figure 21(b)). Most of the study area has predominant frequency of $3 \mathrm{~Hz}$ to $12 \mathrm{~Hz}$ (except at 7 locations in microtremor studies from site response using SHAKE and microtremor studies) [17]. Seismic microzonation of the city of Delhi-NCR was completed under the sole leadership of NCS-MoES involved data generation, compilation, interpretation and preparation of the report along with the release of the report to the public domain. It is evident from Figure 22(a) \& Figure 22(b) prepared for Peak Amplification (using H/V method, Nakamura Technique), that most of the values are ranging between 4 to 8 , which signifies to the zone of very high impedance contrast at shallow depth of $100 \mathrm{~m}$. And a very few are going beyond 8 are found in the parts of Western Delhi and South Delhi. Amplification factor below 2 is also found for a few locations which has rock domain, however Moderate amplification of 2 to 4 is found on Soft Sediment covering most of the NCT Delhi [35]. Figure 22(b) illustrates the Peak Frequency (PF) Contour Map above firm soil bedrock. Map clearly manifests that $\mathrm{PF}$ values at different locations in NCT-Delhi vary in the range of $0.21 \mathrm{~Hz}-10 \mathrm{~Hz}$, and a very few sites have PF in range between $0.1 \mathrm{~Hz}$ to $0.2 \mathrm{~Hz}$. It suggests that NCR Delhi has different frequency ranges categorized into four categories, such as very low peak frequency $(0.12 \mathrm{~Hz}$ to $1.0 \mathrm{~Hz})$; moderate peak frequency $(1.0 \mathrm{~Hz}$ to $2.0 \mathrm{~Hz})$; High peak frequency $(2.0 \mathrm{~Hz}$ to $3.5 \mathrm{~Hz})$; very high peak frequency $(>3.5 \mathrm{~Hz})$. Belts in and around the Yamuna river, extending to its further east to east Delhi is conspicu- 
ously associated with moderate to very high peak frequency, while the majority area of NCR Delhi is associated with peak frequency range of $0.5 \mathrm{~Hz}$ to $1.0 \mathrm{~Hz}$, barring its northern most area shows peak frequency variation from $0.12 \mathrm{~Hz}$ to $0.3 \mathrm{~Hz}$ that corresponds to very low peak frequency zone [35]. Based on extensive geotechnical investigations both at the site and in the laboratory, PGA map and various sub-surface depth and at engineering bed rock, liquefaction map, and
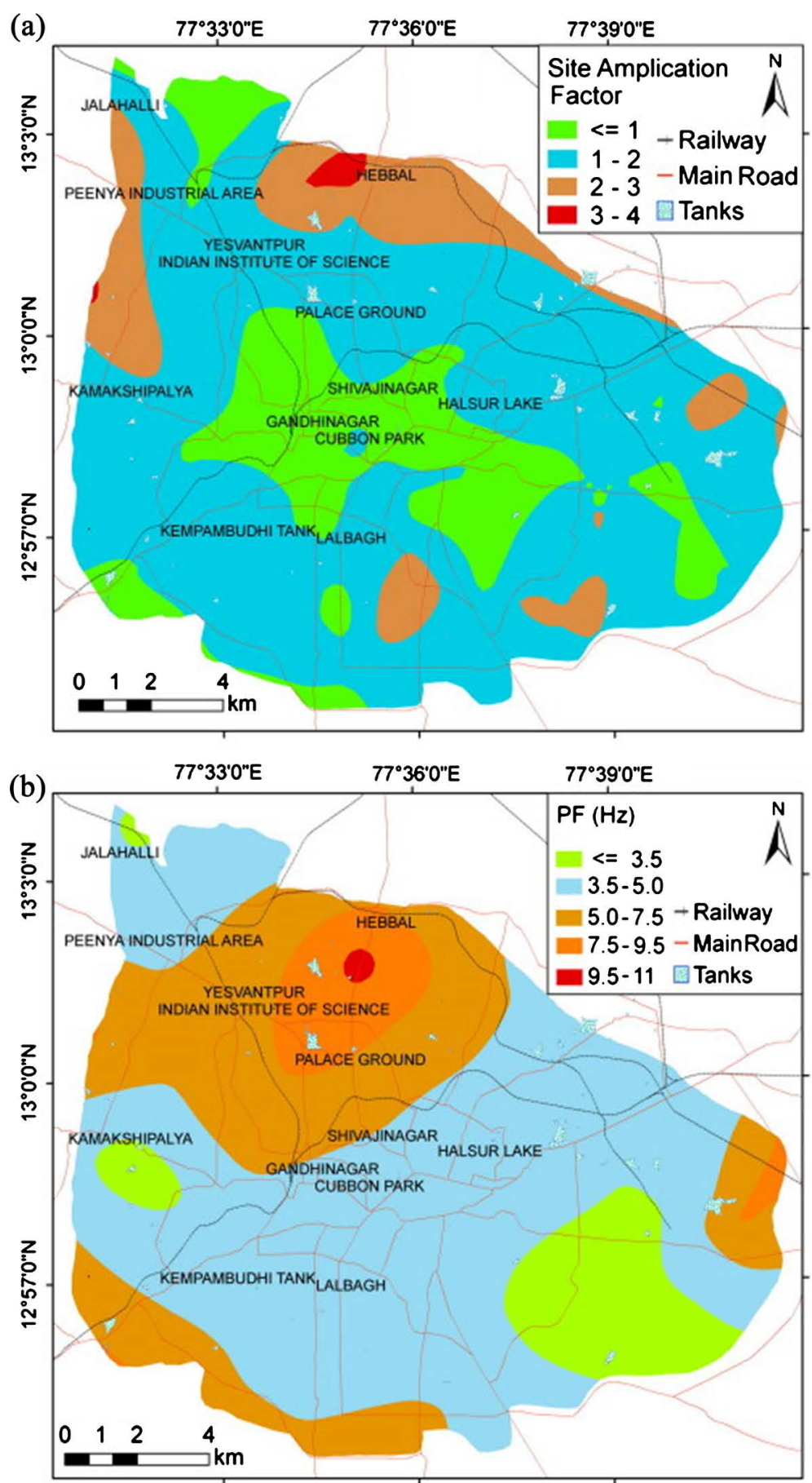

Figure 21. (a) Figure showing Amplification Factor for Bangalore City [34]; (b) Figure showing Peak Frequency for Bangalore City [34]. 


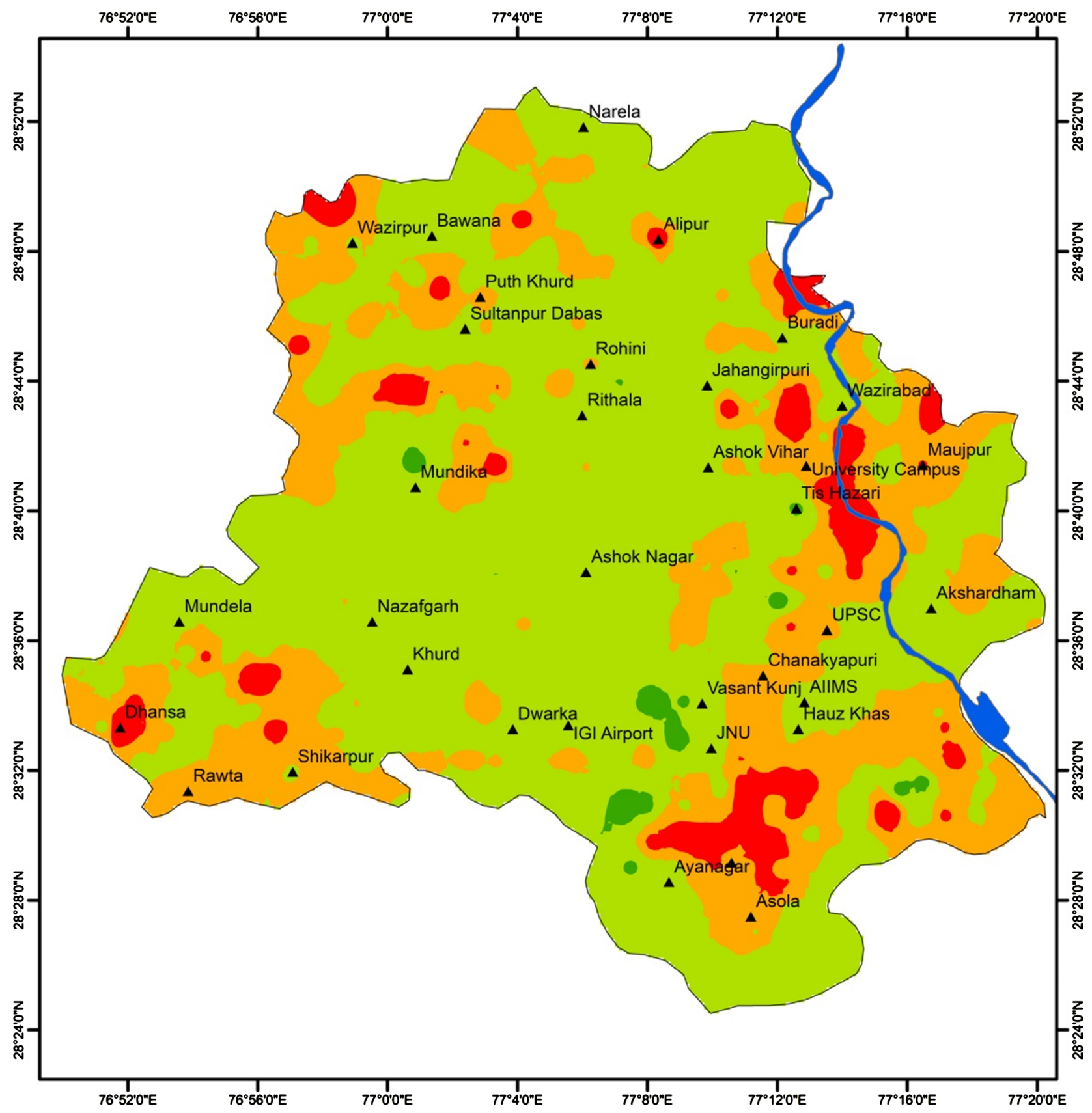

$\simeq \begin{aligned} & \text { Yamuna River } \\ & \text { Delhi Boundary }\end{aligned}$

Peak Amplification

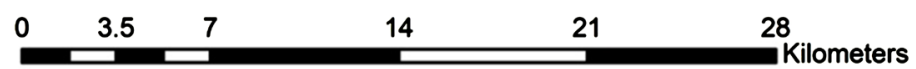

$1.1-2$

$2-4$

4- 6

6-11.54

(a) 


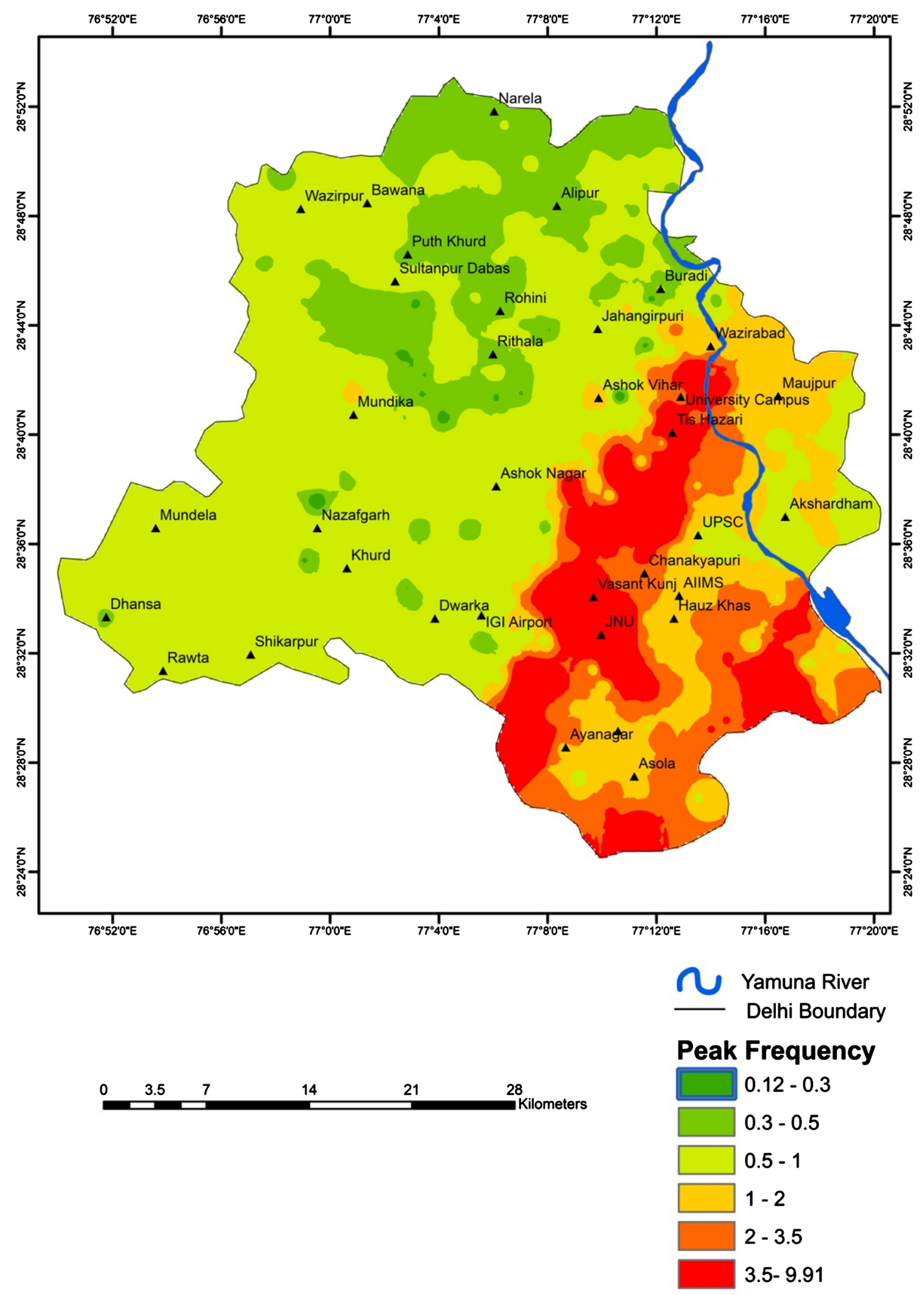

(b)

Figure 22. (a) Peak Amplification Map of NCR-Delhi based on H/V ratio [35]; (b) Peak Frequency Map of NCRDelhi based on H/V ratio [35]. 
earthquake risk index map were also generated for evolving new design codes for making Delhi-NCR as risk resilient [35]. While Building of various Priority/ Public Utility structures, these maps need to be taken in account so that to avoid resonance with ground shaking, which can increase the frequency by the factor of 7 to 20 [35].

\subsection{Nepal}

Nepal lies within the tectonically active Himalayan belt and occupies about one third of the Himalayan arc. The presence of three main fault lines: the Main Central Thrust (MCT) at the foot of the Greater Himalaya joining the midland mountains, the Main Boundary Fault (MBF) at the junction of the Lesser Himalaya and the Siwaliks and the Himalayan Frontal Fault south of the Siwaliks, each running east to west, are the main causes of earthquakes of small and great magnitude in Nepal. History of earthquakes in Nepal could be traced back to $1255 \mathrm{AD}$ when one third of population of Kathmandu was devastated with heavy losses of human population, residential buildings and temples. One of the most devastating earthquakes in the recent past was that of 1934 (M 8.3) when about 8519 people died, out of which 4296 died in the Kathmandu valley alone. Over 200,000 buildings and temples were destroyed. The Udaypur Earthquake of 1988 killed 721 people, jolted 22 districts of Nepal and caused a direct infrastructural loss of 5 Billion Napalese Rupees. This earthquake became an eye opener in the country and the earthquake disaster was considered a major concern for the first time. Both the earthquakes of 1934 and 1988 caused devastation in India as well [2]. Recently, the $25^{\text {th }}$ April 2015 Gorkha-Nepal earthquake cause huges losses to property and lives of people by breaking all past records of human and economic losses happened in the annals of disastrous earthquake of Nepal. According to past experiences and estimates by seismologists, Kathmandu valley has emerged as one of the hot spots of South Asia which is at a very high seismic risk, therefore, lot of studies have been carried in the recent past. Kathmandu Valley Earthquake Risk Management Project (KVERMP) by the National Society for Earthquake Technology (NSET) in association with Geo-Hazards International (GHI), USA revealed that in the event of a possible repeat of the 1934 and the 2015 earthquake in modern-day Kathmandu Valley, the losses would be unprecedented. Attempts have also been made on microzonation in Kathmandu as well as Pokhra valley. Significant attempts have been made to generate awareness and to train manpower for building seismic resistant buildings in Nepal particularly in Kathmandu valley by various agencies such as NSET, National Seismological Centre (NSC), Govt. of Nepal and Khowpa Engineering College [2]. It has been reported that earthquake-induced landslides and GLOF as components of Seismic Hazard Zonation need to be recognized in any seismic microzonation programme for Nepal. Continued collision between the Indian and Tibetan plates combines with its environmentally over-stretched mountainous terrain, adverse geology, glacial lake outburst floods, overgrazing of pro- 
tective cover, monsoonal climate and unprecedented anthropogenic activity to make Nepal hugely vulnerable to earthquake-induced landslides. Despite this widely accepted factor of grave concern in Seismic Hazard and Risk Assessment, seismic zonation programmes have not paid much attention to it [17]. It has been reported that Nepal is divided into five major geological zones from south to north. These are Terai Zone, Churia (Siwalik zone), lesser Himalayan Zone, Higher Himalayan Zone and Tibetan Tethys zone. Terai zone, made-up of Pleistocene to Recent alluvium represents the northern edge of large alluvial IndoGangetic basin, and naturally demands added attention to the considerations of ground amplification, site effects and liquefaction hazard mapping [17], but it has no comprehensive seismic microzonation for several cities of Nepal except Kathmandu and Pokhra, which need to be investigated in detail as per the framework applicable for south Asian countries. The distribution of peak resonant frequencies is mostly observed in the frequency range of $4 \mathrm{~Hz}$ to $6 \mathrm{~Hz}$, in the central and northern part of the valley, and also near the bank of the river. The ratio of second resonant frequencies to the first resonant frequencies is found to be approximately $5 \mathrm{~Hz}$. The amplitude of the second peak frequencies vary from place to place, but are found higher than the amplitude of the first peak frequencies in most of the locations. These frequencies are linked with the presence of the surface layer. This indicates that the bottom strata of the surface layer should have a sufficient impedance contrast compared to the layer underneath.

\subsection{Pakistan}

Large tracts of Pakistan lie within a seismically active Himalayan belt where the Suleiman, Hindu Kush and Karakoram mountain ranges, the northern areas, Chitral districts in NWFP, Quetta, Chaman, Sibi, Makrana coast and parts of Balochistan are located in high or very high risk areas. Cities of Islamabad, Karachi and Peshawar are located on the edges of high risk areas. Five major earthquakes have hit Pakistan including: 1935 Quetta earthquake, 1945 Makrana coast earthquake, 1976 Northern Areas, 2005 Kashmir earthquake and most recently 2008 Balochistan earthquake also showed a great impacts on buildings and infrastructures. Geological Survey of Pakistan in 1974 prepared a map of seismic intensities and earthquake hazard zones of Pakistan (Figure 23). As per the latest seismic zoning map reported by [36], the country has been divided into four seismic hazard zones based on the Earthquake data (historical and instrumental) and observed intensities: Zone-I: Very high hazard zone with Seismic Factor ranging from $g / 5$ to $g / 10$. This zone is liable to major damage due to earthquakes; Zone-II: High Hazard zone with Seismic Factor ranging from g/10 to $\mathrm{g} / 15$. This zone is having a possibility of moderate seismic damage; Zone-III: Moderate hazard zone with Seismic Factor ranging from $g / 15$ to $g / 20$. This zone may experience minor damages due to earthquake; Zone-IV: Low hazard zone with Seismic Factor equal to $\mathrm{g} / 20$ or less. This is the safest zone with negligible expected damage. It has been reported that Pakistan lies in a region with moderate 


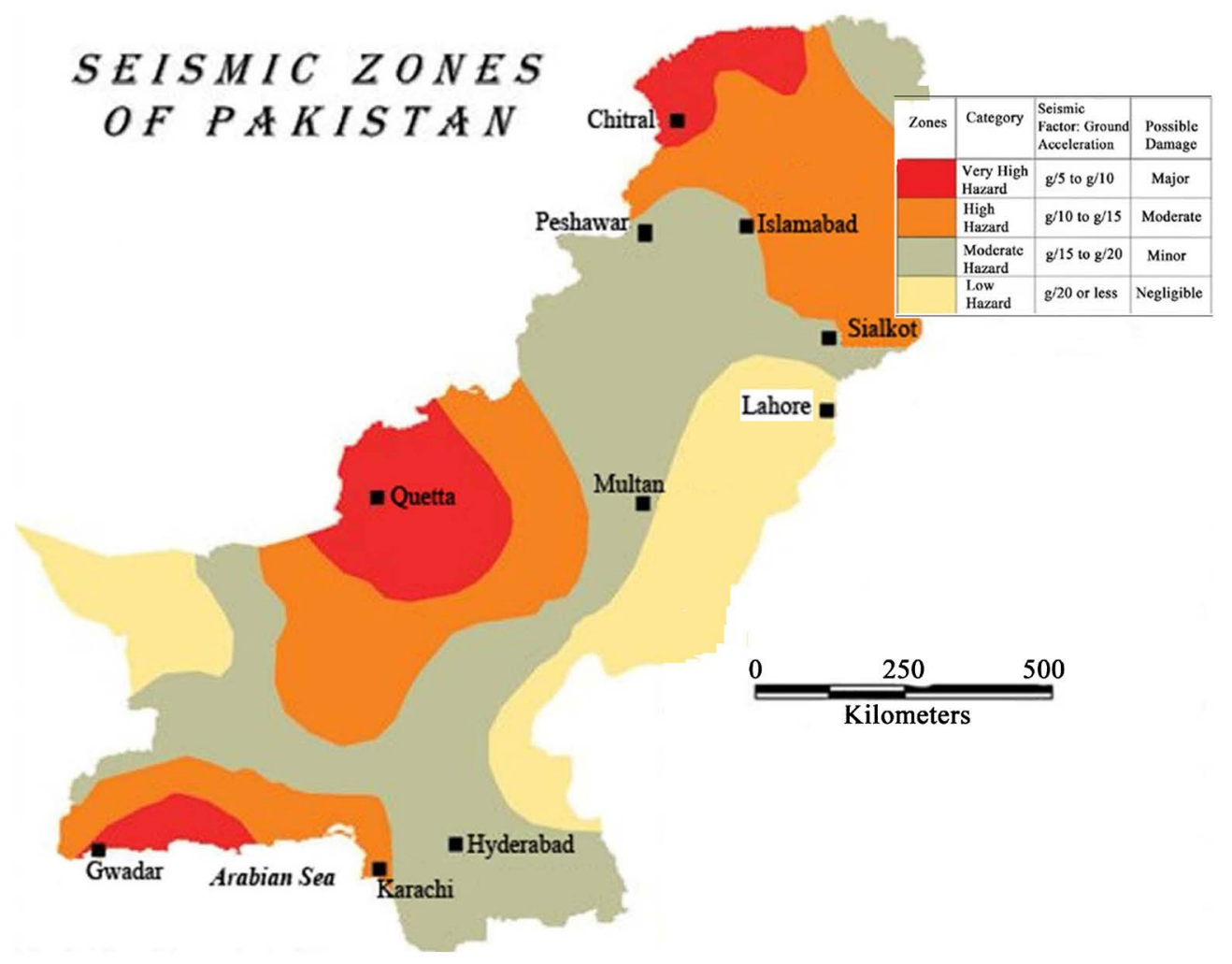

Figure 23. Seismic hazard map of Pakistan with some of its important cities shown in the map (after Pakistan Meteorological Department) [2] [17] [36].

to high seismic hazard; the greatest hazard is in parts of the North West Frontier Province (NWFP), in the vicinity of Quetta and along the border with Iran. Historically, earthquakes in the M7.0 range have been experienced in Balochistan and along the border with Afghanistan and India. Recent earthquake around Balochistan has once again revealed the vulnerability of the region [2]. The first initiative to prepare seismic hazard map of Pakistan came from the Global Seismic Hazard Assessment Programme (GSHAP). This map is based on global earthquake catalogues and provides values of PGA with $10 \%$ probability of exceedance in 50 years. The most recent stimulus for the government of Pakistan to develop a revised national seismic hazard map came after the deadly Muzaffarabad earthquake of 2005. The zonation map divides Pakistan into four seismic hazard zones. Zone 4 is most hazardous and Zone I is the least. Pangu, Kalat, Quetta, Sibi, Dera Gazi Khan, Dera Ismail Khan, Mianwall, Islamabad, Peshawar, Abottabad and Chitral all falls in the Zone 4 [17].

Pakistan has generated amplification and the corresponding peak frequency maps for the 2005 Muzaffrabad earthquake (Mw 7.8) zone, and found the variability of sub-surface formation, which has high bearing on assessing the impacts of earthquake shaking on buildings and infrastructure, even if much effort is required to develop risk resiliency of cities in Pakistan in accordance to the framework of seismic microzonation for SAR.

Figure 24(a) shows Peak Amplification (using H/V method, Nakamura Tech- 


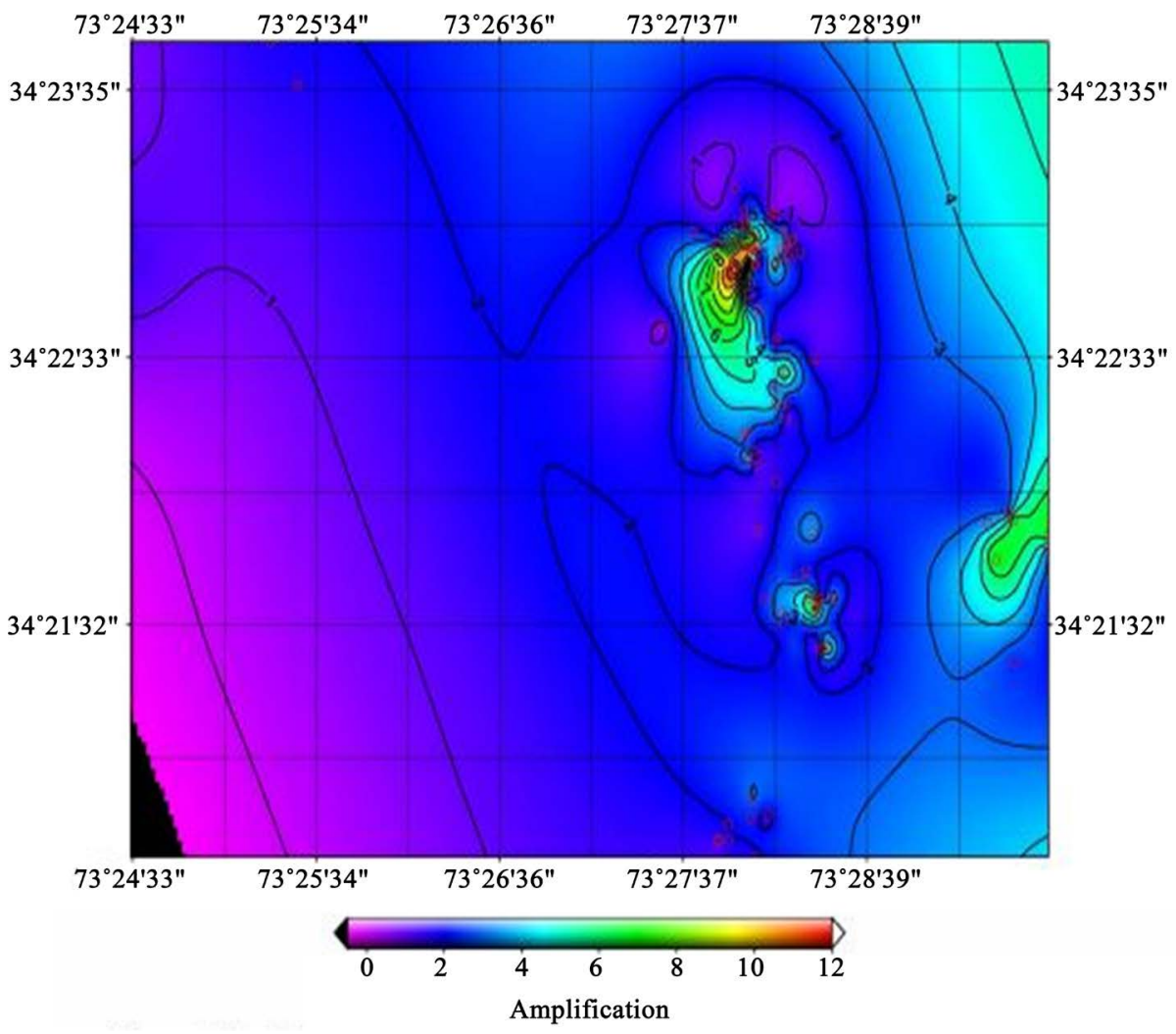

(a)

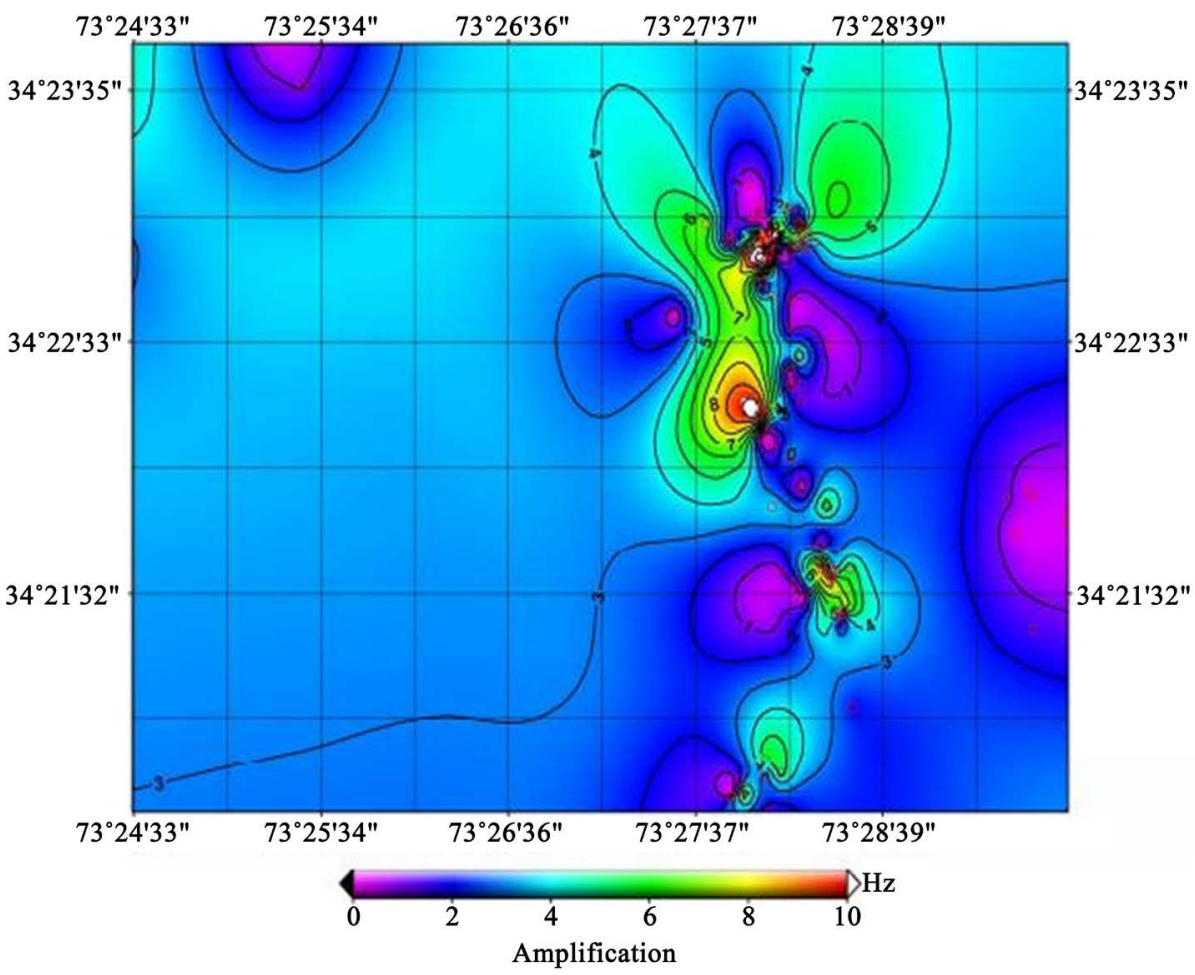

(b)

Figure 24. Map of Muzaffarabad city, showing the Fundamental frequencies of the site range $0-10 \mathrm{~Hz}$. 
nique), that most of the values are ranging between 4 to 8 , which signifies to the zone of very high impedance contrast at shallow depth of $100 \mathrm{~m}$. Amplification factor below 2 is also found for a few locations, towards the western side, which may have rock domain, however Moderate amplification of 2 to 4 is found on Soft Sediment covering most of the Muzaffarabad city, Pakistan [2]. Figure 24(b) illustrates the Peak Frequency (PF) Contour Map above firm soil bedrock. Map clearly manifests that $\mathrm{PF}$ values at different locations in Muzaffarabad city, Pakistan varies in the range of $0.21 \mathrm{~Hz}-10 \mathrm{~Hz}$, and a very few sites have high PF in range between $8 \mathrm{~Hz}$ to $10 \mathrm{~Hz}$, alongwith patches of frequency ranging in $5 \mathrm{~Hz}$ to $8 \mathrm{~Hz}$ while the majority area of Muzaffarabad city is associated with peak frequency range of $0.5 \mathrm{~Hz}$ to $1.0 \mathrm{~Hz}$ [2].

\subsection{Sri Lanka and Maldives}

Both Sri Lanka and Maldives have threat to loss of lives due to tsunamigenic earthquakes beneath Indian Ocean and its adjoining seismogenic zones. Sri Lanka lies in a region of low seismic hazard. Historically, mild earthquakes have been experienced in different parts of the island. Onshore hazard is low but earthquakes in the M 5.0 - 6.0 range have occurred in the Gulf of Mannar in historical past that were felt all over Sri Lanka. M7+ events originating in the Sumatra-Andaman arc and events in the M6 range originating in the north Indian Ocean have also been felt. Although Sri Lanka is far away from the plate boundaries, yet it is close enough to the highly active seismic zone near Sumatra and other regions to its South-East so that earthquakes generated in this region may lead to a Tsunami Hazard in Sri Lanka as experienced during the 2004 event that devastated much of the east and south coasts, claiming more than 35,000 lives and displacing over half a million people [2].

Similarly, although the Maldives enjoys very low seismic hazard propensity in terms of ground shaking, it remains one of the most vulnerable country to tsunami effect due to major earthquakes in the Indian Ocean as it was severely affected by the 2004 tsunami. Tidal waves ranging from 1.2 to 4.2 meters swept across most parts of the country. Out of the 198 inhabited islands, 13 were rendered not habitable, 56 sustained major physical damage, and 121 were impacted by moderate damage due to flooding. Over 100 people were killed and more than 6000 houses were either destroyed or severely damaged [2]. Even if in order to have precise information on geo-mechanical strength of soil layers are very much warranted for building safer structures under climate change scenario.

It is observed that precise estimates of physical property contrasts of soil and basement rock with sensitive variation in the acoustic impedance contrast at the smallest scale of investigations are the need of hour. As mentioned above, in order to assess the impacts of earthquake shaking on very closely spaced objects, there is a need to undertake geophysical and geotechnical investigations applying the concept of seismic nan-zonation, seismic pico-zonation, and seismic femto-zonation by which the smallest object with its smallest dimension can be 
investigated for addressing the issue of vitality to make the construction not only earthquake risk resilient but earthquake risk proof using the newest dynamic design codes (Figure 25).

\subsection{GIS-Based Seismic Microzonation for SAR}

It has been accepted that the development in Geographic Information System (GIS) and its versatility have revolutionised its applicability in Geosciences, especially to deal with several natural disaster programs. The amount, quality and cost of information required for mapping generally increases with greater levels of certainty. Collected data can then be processed into a series of GIS layers followed by quantitative evaluation of hazard potential, which can be adopted as a primary working tool in preparing seismic hazard microzonation attributes for the city concerned [37]. None of SAR countries applied GIS-approach in beginning in presenting their seismic microzonation reports following the acceptable framework (Figures 26-28). But now SAR is using the GIS tool gradually for better and plausible explanation of comprehensive results of Seismic micro zonation. Among which India is leading in applying the tool for her all cities, which have been covered by seismic Microzonations under 30-cities in India. It is so because multitasking functionality of GIS makes it ideally suited for seismic microzonation as it enables automation of data analyses and information of thematic layers. Besides the ability of GIS to handle large volume of data, its flexibility, accuracy and its capability to upgrade the database and to integrate the same in a short time has proved to be indispensable in the field of seismic microzonation is well documented [37]. At the regional level, it can be used in the hazard assessment for resource analysis and project identification, while, at

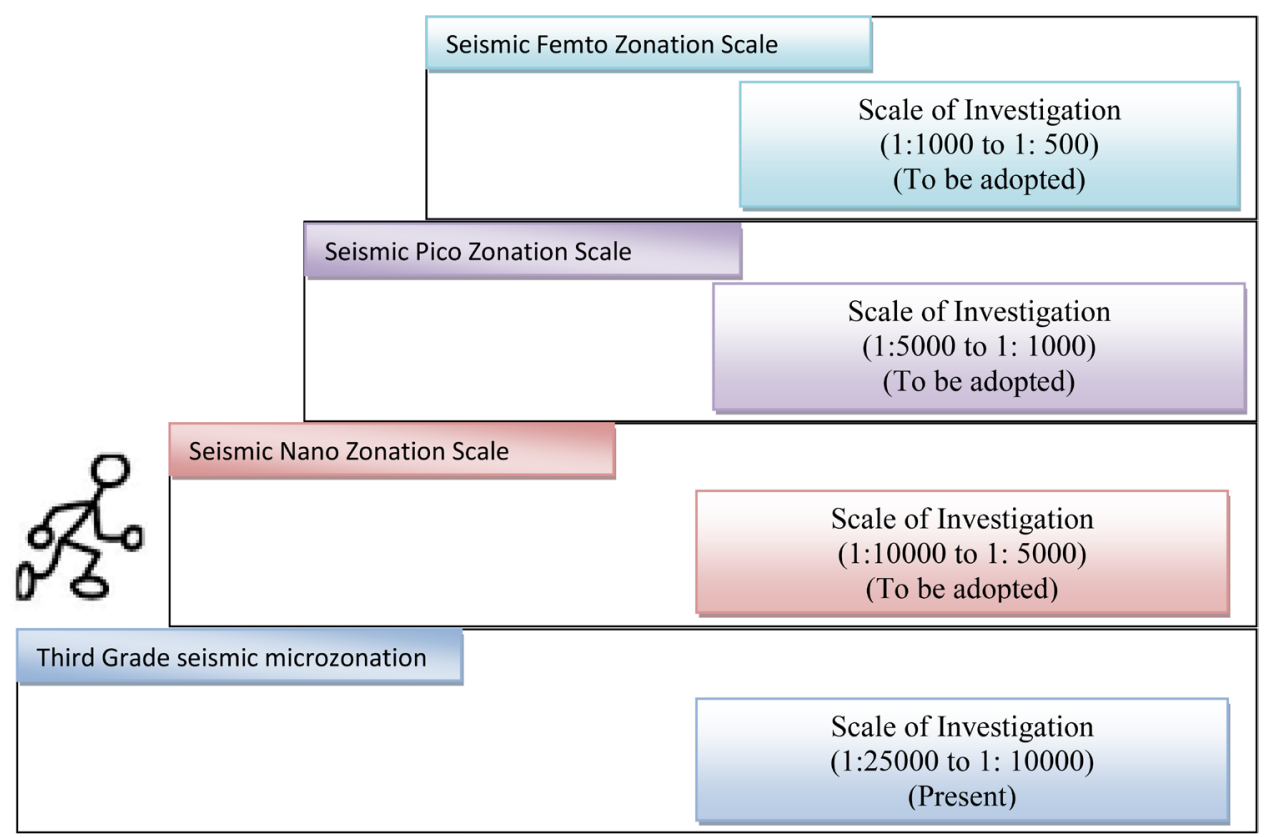

Figure 25. Advanced Grades of Seismic Zonation for safer and Earthquake Risk Resilient Urban Agglomerates proposed in this study. 


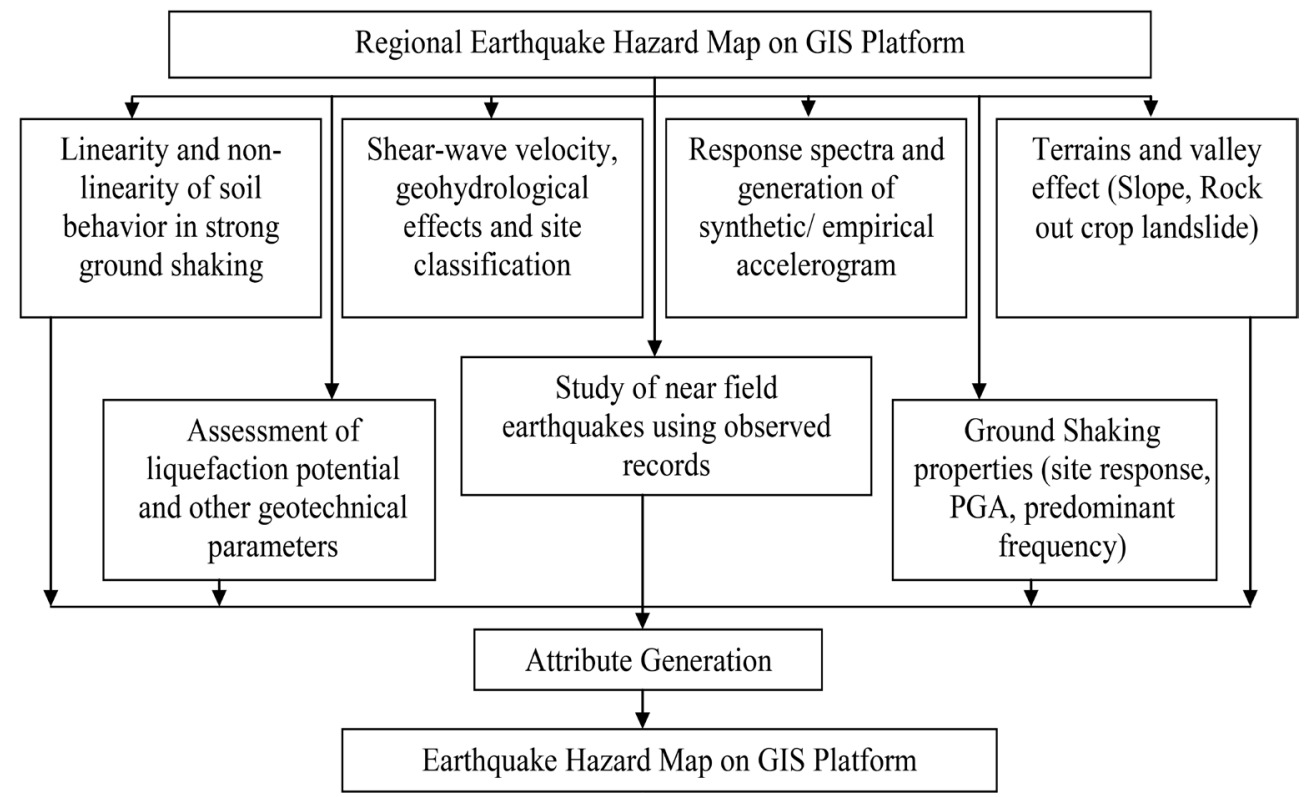

Figure 26. Regional Earthquake Hazard Map on GIS Platform based on the Roadmap developed by SAARC Disaster Management Centre in the year 2011 [17].

the local level, it can be used to formulate investment projects and specific mitigation strategies. Therefore, it is hard to conceive a micro-seismic programme without its very intimate coupling with GIS [37]. Earthquakes create the highest risks of catastrophic damages. Recovering from the damages and destructions of earthquakes and reconstructing the lives of households, communities, cities and villages that involve multiple sectors-housing, infrastructure, livelihood, health, education, environment etc.- have been one of the daunting tasks of disaster management. SAARC Disaster Management Centre can play important role in documentation and sharing of such good practices in the region.

\section{Conclusions and Recommendations}

In this study, it is observed that the existing framework of earthquake risk assessment on national level is not apt to achieve resiliency of the urban agglomerates of South Asian earthquake-prone countries (Afghanistan; Bangladesh; Bhutan, India, and Pakistan) as those seismic macrozoning maps have compromised several geophysical, seismotectonical and geotechnical parameters that dictate the nature and extent of impacting constructions and infrastructures located in the respective seismic hazard zones. It is also noted that India through its Ministry of Earth Sciences has gained a sufficient breakthrough in generating citybased comprehensive mircozonation maps associated with GIS attributes in accordance to the world standard guidelines in form of manual and handbook of seismic microzonation in a mission mode so that generated outputs can be used to evolve the city-specific building design codes. The similar concept of India can be applied by other countries of SAR for preparing city-based seismic microzonation maps to achieve earthquake risk resiliency for urban agglomerates 


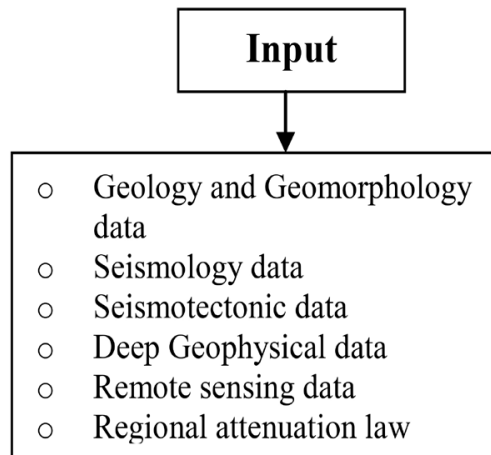

\begin{tabular}{|cl}
$\circ$ & Topographic Maps \\
$\circ$ & Geotechnical Investigations \\
& and data \\
$\circ$ & Geophysical Investigations \\
& and data \\
$\circ$ & Hydro-geological \\
& Investigations and data
\end{tabular}

\begin{tabular}{|cl|}
\hline$\circ$ & Bed Rock motion data \\
$\circ$ & Subsoil profiling and ground \\
& surface topography \\
$\circ$ & Hydro geological data \\
$\circ$ & Dynamic soil properties \\
$\circ$ & Experimental study- \\
& Microtremor
\end{tabular}
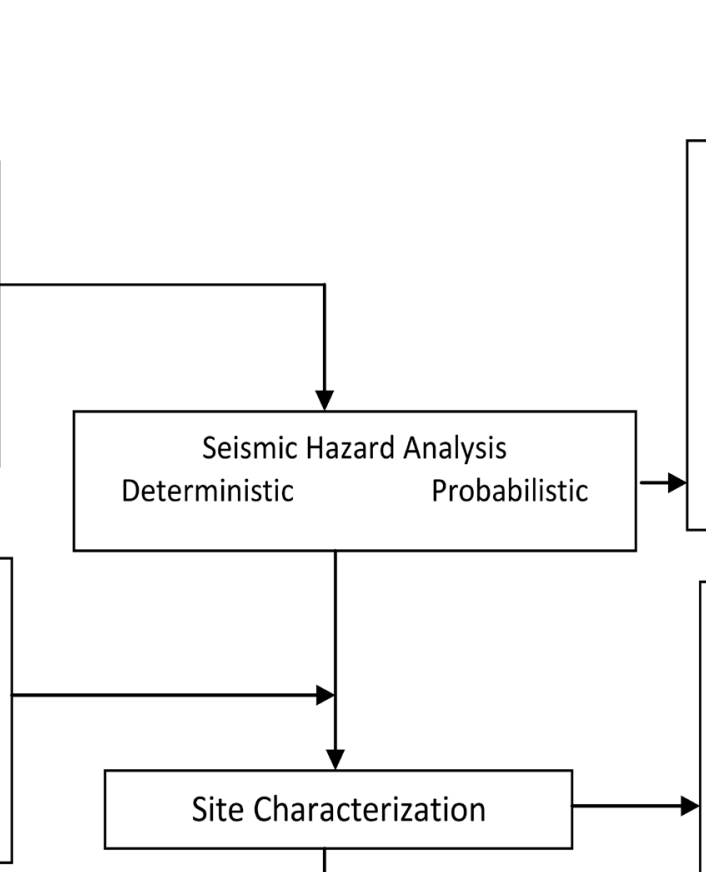

- PGA at Ground level

- Earthquake Magnitude

- Stress history, in situ stresses and Soil properties

- Representative corrected "N" value

- Experimental studies

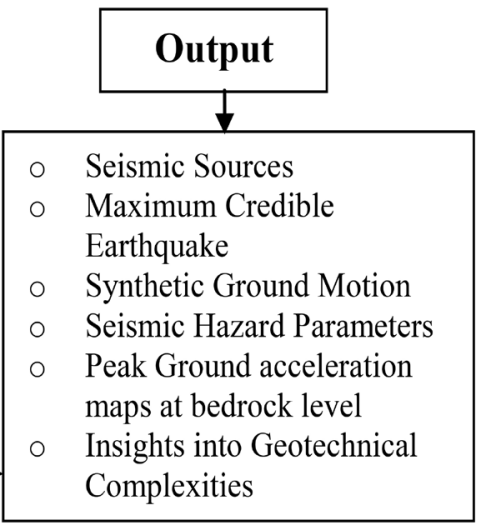

- Two and three dimensional sub-surface profiling and Bedrock mapping

- Modeling of subsurface soil deposits

- 3-D borehole models Insitu and Lab test results, correlations and statement on uncertainities

- Vs mapping

- $\mathrm{Vs}^{30}$ mapping

$\left(\mathrm{N}_{1}\right)$ versus Vs Relations

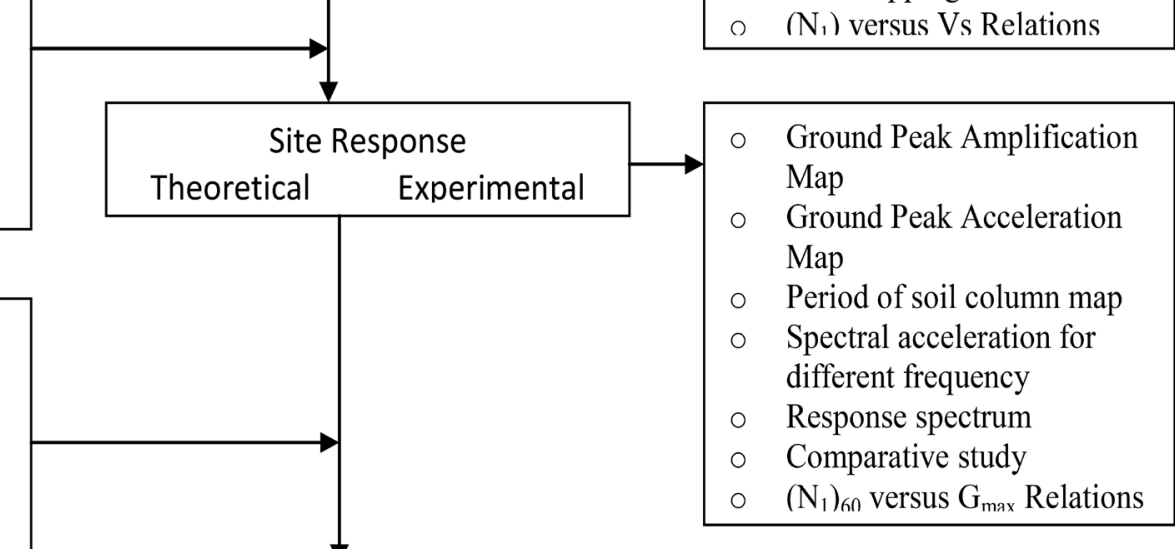

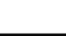

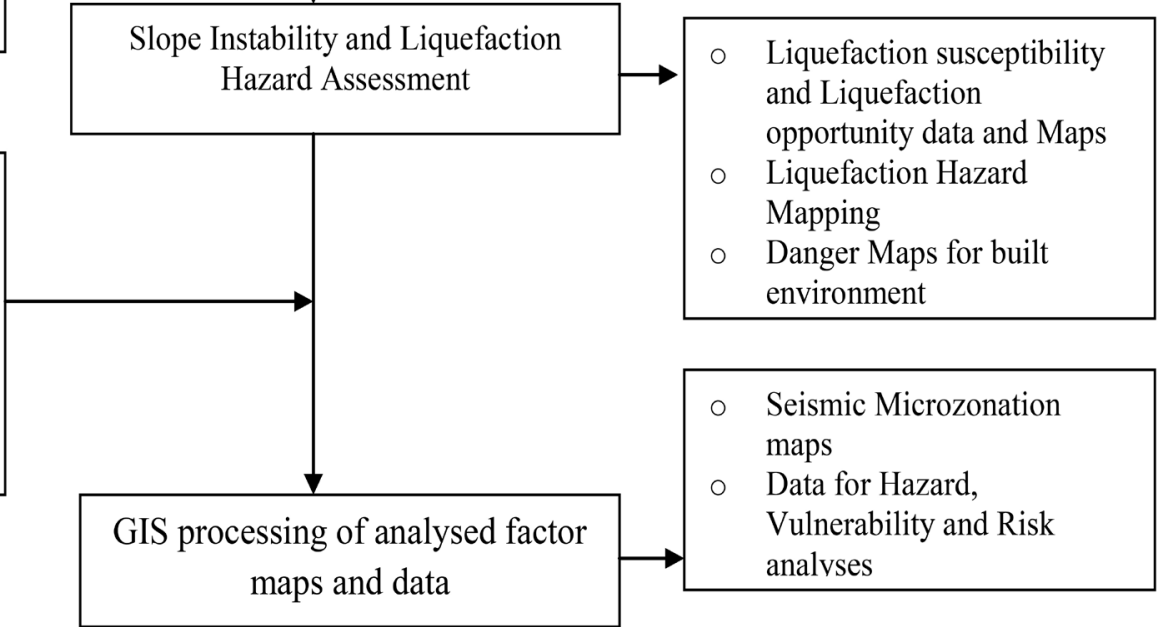

Figure 27. Flow Chart for seismic hazard and microzonation proposed for the Urban Centre (India) [17]. 


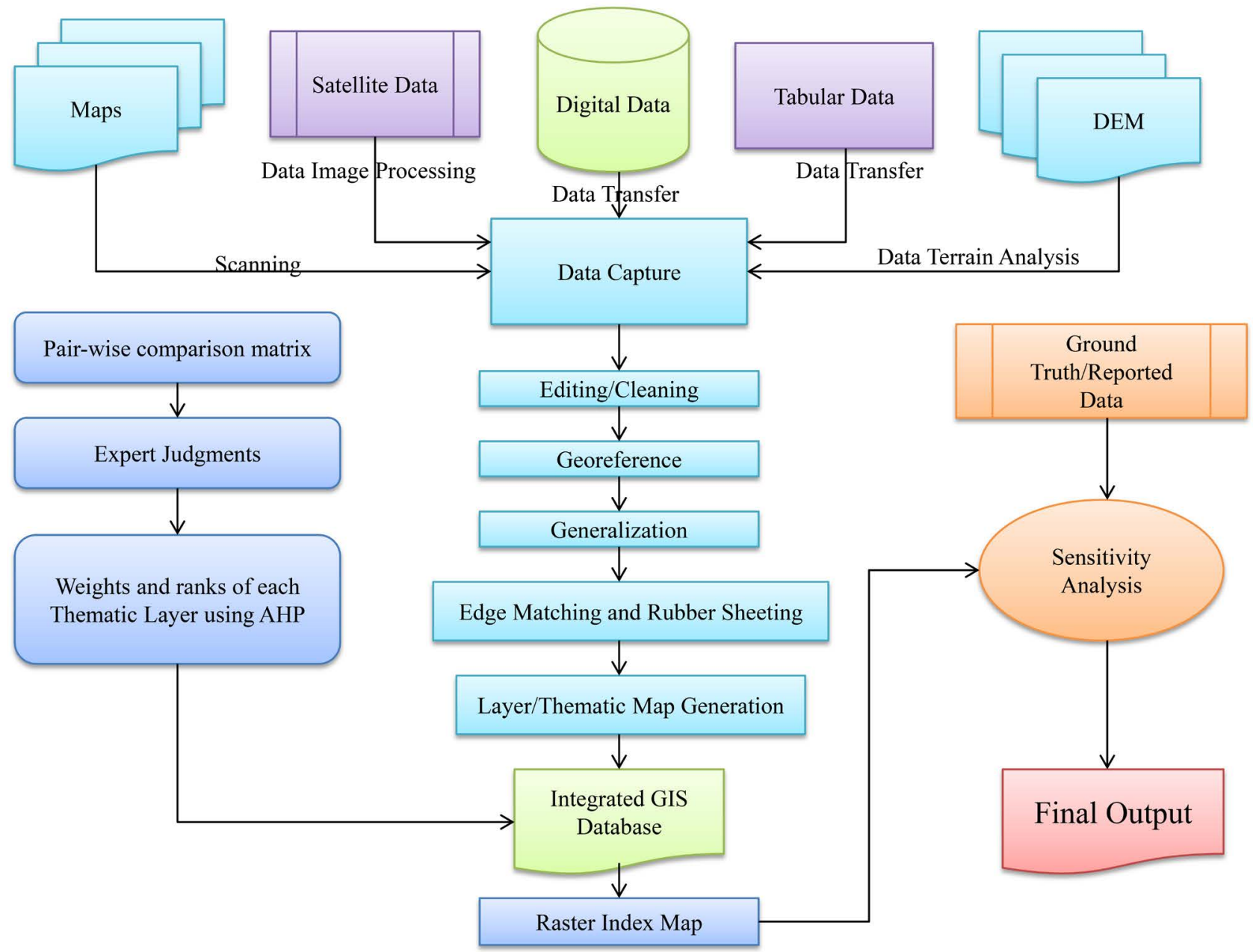

Figure 28. A schematic process flow in GIS based Thematic Mapping and Spatial analysis (adapted from [37]).

of the region under uncontrollable climate change scenario. The existing infrastructures can be retrofitted to mitigate and reduce the nature and extent of damages to structures whilst site response based comprehensive seismic microzonation is very much required for new settlements and for long-term sustainable urban planning by adopting multi-disciplinary investigations using integrated tools consisted of geophysical, geological, and geotechnical methodologies, which in turn help understand how and why underneath sub-surface layers get amplified to cause destruction of buildings and severe damages to critical infrastructures of South Asian Cities.

The wealth of information related to geophysical, geological, seismological, geotechnical data generation at the plausibly smallest scale of investigation is the greatest challenge and to constrain in generating city-based seismic microzonation maps for SAR. There is a need to have dense and updated seismographic and accelerographic network in the earthquake-prone countries of SAR so that empirical ground motion generation can be compared with observed data at the site and such endeavour will help to generate reliable and deterministic model for safer design. It is inferred that implementation of fourth level comprehensive 
Seismic Nano, Pico and Femto zonation study for almost all strategic cities of South Asia is a need of an hour in general, and is very important for generating a series of new parameters in particular for development of multi-dimensional risk resilient building design codes applicable to different kinds of structures and typology of the buildings. The impacts of secondary effects generated by earthquakes, such as landslide, tsunami and GLOF may be incorporated into seismic hazard maps for seeking comprehensive information, which can easily be achieved by SAR through knowledge and technology sharing with multi-institutional collaborative efforts for which sufficient financial support may be provided by the respective national government of SAR. Depending up on the vitality of the risk resiliency of the structures to be constructed, the outcomes of detailed site specific studies based on the concept of seismic microzonation needs to be extended to seismic nanozonation, seismic picozonation, and to seismic femtozonation. The respective national government of SAR in association with its partner agencies may adopt the said modality with proper guidelines on legal and financial safeguards for the development of the sustainable risk resilient buildings and infrastructures in the respective country. The mission of providing risk resilient structures to the urban agglomerates of countries under SAR would be successful by involving public-private partnership with insurance and assurance of legal a binding on purchasers and sellers of the built structures in the respective SAARC Member states, especially for the safety of the urban residents.

\section{Acknowledgements}

Author acknowledges sincere thanks to various agencies of SAARC Member States for using their reports available on public domains. Motivating environment provided by the Secretary, Ministry of Earth Sciences (MoES), and Director, National Centre for Seismology (NCS) gratefully acknowledged. Sincere help in data compilation and useful suggestion by Mr. Mrigank Ghatak, Director, Geological Survey of India; Ms. Priya Singh, Project Scientist-B, NCS, MoES and Ms. Sasi Kiran Gera, Research Associate, NCS, MoES is sincerely acknowledged. Author is thankful to anonymous reviewers and R. Wong of IJG for their constructive comments and suggestions that improved the original manuscript significantly.

\section{Conflicts of Interest}

The author declares no conflicts of interest regarding the publication of this paper.

\section{References}

[1] Mishra, O.P. and Ghatak, M. (2020) SAARC: A Regional Perspective. Geography and You, 20, 80-87.

[2] SAARC (2009) Workshop on Earthquake, Risk Management in South Asia, 8-9 October 2009, Islamabad, Pakistan.

[3] Valdiya, K.S (2010) The Making of India Geodynamic Evolution. Macmillan Publ., 
New York, 816 p.

[4] Mishra, O.P., Kayal, J.R., Chakrabortty, G.K., Singh, O.P. and Ghosh, D. (2007) Aftershock Investigation in Andaman-Nicobar Islands of India and Its Seismotectonic Implications. Bulletin of the Seismological Society of America, 97, S71-S85. https://doi.org/10.1785/0120050629

[5] Mishra, O.P., Chakrabortty, G.K., Singh, O.P., Kayal, J.R. and Ghosh, D. (2007) Aftershock Investigation in the Andaman-Nicobar Islands: An Antidote to Public Panic. Seismological Research Letters, 78, 591-600.

https://doi.org/10.1785/gssrl.78.6.591

[6] Srivastava, R.K. (2017) Catastrophe of Climate Change and Urbanization in SAR. Unpublished Ph.D. Thesis, $437 \mathrm{p}$.

[7] UN Habitat (2010) State of the World's Cities, 2010/2011 Bridging the Urban Divide. https://sustainabledevelopment.un.org/content/documents/11143016_alt.pdf https://doi.org/10.4324/9781849774864

[8] Lyon-Caen, H. and Molnar, P. (1985) Gravity Anomalies, Flexure of the Indian Plate, and the Structure, Support, and Evolution of the Himalaya and Ganga Basin. Tectonics, 4, 513-538. https://doi.org/10.1029/TC004i006p00513

[9] Nakata, T. (1989) Active Faults of the Himalaya of India and Nepal. Geol. Soc. of America Spec. Paper, 232, 243-264. https://doi.org/10.1130/SPE232-p243

[10] Yeats, R.S., Nakata, T., Farah, A., Fort, M., Mirza, M.A., Pandey, M.R. and Stein, R.S. (1992) The Himalayan Frontal Fault System. Annales Tectonicase, 6, 85-98.

[11] Bilham, R. (1995) Location and Magnitude of the 1833 Nepal Earthquake and Its Relation to the Rupture Zones of the Contiguous Great Himalayan Earthquakes. Current Science, 6992, 155-187.

[12] Bilham, R., Bodin, P. and Jackson, M. (1995) Entertaining Great Earthquakes in Western Nepal: Historic Inactivity and Geodetic Test for Development of Strain. Journal of Nepal Geological Society, 11, 73-78.

[13] Bilham, R., Gaur, V.K. and Molnar, P. (2001) Himalayan Seismic Hazard. Science, 293, 1442-1444. https://doi.org/10.1126/science.1062584

[14] Bilham, R. (2004) Earthquakes in India and the Himalaya: Tectonics, Geodesy and History. Annals of Geophysics, 47, 839-858.

[15] Ambraseys, N. and Jackson, D. (2003) A Note on Early Earthquakes in Northern India and Southern Tibet. Current Science, 84, 571-582.

[16] Mishra, O.P. (2014) Intricacies of the Himalayan Seismotectonics and Seismogenesis: Need for Integrated Research, Special Section: Science of the Himalaya. Current Science, 106, 176-187.

[17] SAARC (2011) Seismic Microzonation: Methodology for Vulnerable Cities of South Asian Countries. SAARC Disaster Management Centre, New Delhi.

[18] RFP-MoES (2017) Geotechnical and Geophysical Investigation of 30 Cities under the Project "Seismic Microzonation of 30 Cities in India". https://www.moes.gov.in/writereaddata/files/RFP_NCS-SHRA_Final_15052017.pdf

[19] Mohanty, M. (2005) Symposium on Seismic Hazard Analysis and Microzonation, September 23-24, 2005.

[20] Zhang, P., Yang, Z.X., Gupta, H.K., Bhatia, S.C. and Shedlock, K.M. (1999) Global Seismic Hazard Assessment.

[21] Waseem, M., Lateef, A., Ahmad, I., Khan, S. and Ahmed, W. (2018) Seismic Hazard Assessment of Afghanistan. Journal of Seismology, 23, 217-242. 
https://doi.org/10.1007/s10950-018-9802-5

[22] Oldham, T. (1882) A Catalogue of Indian Earthquakes from the Earlier Time to the End of A.D. 1869. Memoirs of the Geological Survey of India, 19, 163-215.

[23] Molnar, P. (1990) A Review of the Seismicity and the Rates of Active under Thrusting and Deformation at the Himalaya. Journal of Himalayan Geology, 1, 131-154.

[24] Champatiray, P.K., Foreste, K. and Roy, P.S. (2001) Bhuj Earthquake, GIS Development, Volume V, N-8.

[25] Champatiray, P.K., Perumal, R.J.G., Thakur, V.C., Bhat, M.I., Mallik, M.A., Singh, V.K. and Lakhera, R.C. (2005) A Quick Appraisal of Ground Deformation in Indian Region Due to the October 8, 2005 Earthquake, Muzaffarabad, Pakistan. Journal of ISRS, 33, 465-473. https://doi.org/10.1007/BF02990731

[26] Paudiyal, H. and Singh, V.P. (2005) Estimation for the Occurrence of Moderate Size Earthquakes in Central Himalaya, Nepal. Proceedings of Symposium on Seismic Hazard Analysis and Microzonation, Volume I, 187.

[27] Pande, P., Joshi, D.D., Kandpal, G.C., Joshi, K.C., Singh, R.J., Singh, B.K., Singh, J. and Johri, B. (2006) Macroseismic Studies of 8th October 2005 Kashmir Earthquake, 13 SEE 06, Roorkee.

[28] Mahajan, A.K., Slob, S., Ranjan, R., Sporry, R., Champatiray, P.K. and van Westen (2007) Seismic Microzonation of Dehradun City Using Geophysical and Geotechnical Characteristics in the Upper 30-Meters of Soil Column. Journal of Seismology, 4, 355-370. https://doi.org/10.1007/s10950-007-9055-1

[29] Mishra, O.P. (2012) Seismological Research in India. Proceedings of the Indian National Science Academy (PINSA), 76, 361-375.

[30] Arya, A.S. (1992) Possible Effects of a Major Earthquake in Kangra Region of Himachal Pradesh. Current Science, 62, 251-256.

[31] MoES (2011) Seismic Microzonation Manual. 228 p. https://moes.gov.in/writereaddata/files/seismic_mcrozonation_manual.pdf

[32] MoES (2011) Seismic Microzonation Handbook. 507 p. https://moes.gov.in/writereaddata/files/seismic_microzonation_handbook.pdf

[33] NDMA India (2007) National Disaster Management Guidelines, Management of Earthquakes. NDMA Publication, New Delhi.

[34] Anbazhagan, P., Thingbaijam, K.K.S., Nath, S.K., Narendara Kumar, J.N. and Sitharam, T.G. (2010) Multi-Criteria Seismic Hazard Evaluation for Bangalore City, India. The Journal of Asian Earth Sciences, 38, 186-198. https://doi.org/10.1016/j.jseaes.2010.01.001

[35] NCS-MoES (2016) A Report on Seismic Microzonation of NCT-Delhi on 1:10,000 Scale. National Centre for Seismology, Ministry of Earth Sciences (NCS-MoES), New Delhi, 387 p. https://www.moes.gov.in/writereaddata/files/Delhi_microzonation_report.pdf

[36] NDMA Pakistan (2007) Earthquake-8/10: Learning from Pakistan's Experience. NDMA Publication, Islamabad.

[37] Nath, S.K. (2016) Seismic Hazard, Vulnerability and Risk Microzonation Atlas of Kolkata. Geoscience Division, Ministry of Earth Sciences, New Delhi. 